Florida International University FIU Digital Commons

FIU Electronic Theses and Dissertations

University Graduate School

7-28-1988

\title{
A content analysis of food and nutrition television advertisements
}

Lorraine D. Bender

Florida International University

DOI: $10.25148 /$ etd.FI14050496

Follow this and additional works at: https://digitalcommons.fiu.edu/etd

Part of the Dietetics and Clinical Nutrition Commons

\section{Recommended Citation}

Bender, Lorraine D., "A content analysis of food and nutrition television advertisements" (1988). FIU Electronic Theses and Dissertations. 1499.

https://digitalcommons.fiu.edu/etd/1499

This work is brought to you for free and open access by the University Graduate School at FIU Digital Commons. It has been accepted for inclusion in FIU Electronic Theses and Dissertations by an authorized administrator of FIU Digital Commons. For more information, please contact dcc@fiu.edu. 
A CONTENT ANALYSIS OF

FOOD AND NUTRITION TELEVISION ADVERTISEMENTS

by

Lorraine D. Bender

A thesis submitted in partial fulfillment of the requirements for the degree

MASTER OF SCIENCE

in

Dietetics and Nutrition

at

Florida International Uriversity

August 1988 
The thesis of Lorraine D. Bender is approved:
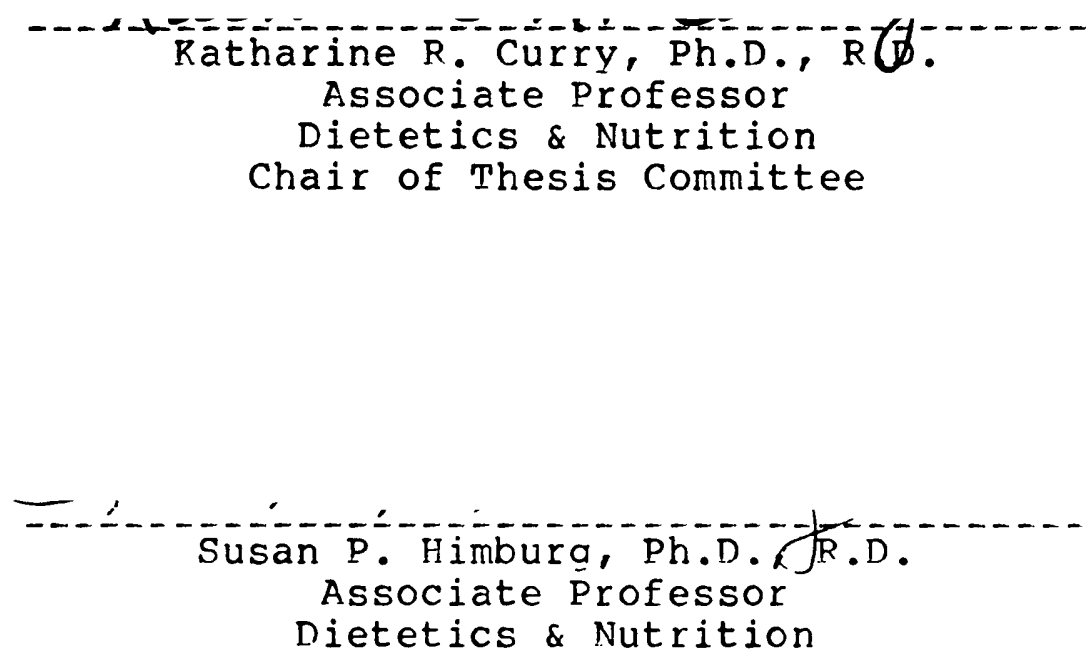

Nanc Weliman, Ph.D., $\mathrm{R} . \mathrm{D}$
Associate Professor
Dietetics \& Nutrition

July 28,1988 
LIST OF FIGURES • • • • • • • • • • • • • • • • • • • • • v

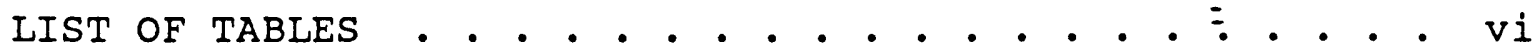

ACKNOWLEDGEMENTS • • • • • • . • • • • • • • • • • • . viii

ABSTRACT . . . . . . . . . . . . . . . . . ix

I. STATEMENT OF THE PROBLEM . . . . . . . . . . . . . I

Introduction . . . . . . . . . . . . . . . 1

Goals of the study . . . . . . . . . . . . . . 2

Research Questions . . . . . . . . . . . 2

Definition of Terms . . . . . . . . . . . . 3

II. RELATED LITERATURE . . . . . . . . . . . . 4

Introduction to Related Literature . . . . . . 4

Financial Aspects of Television Advertising . . 5

Status of Decision Making . . . . . . . . . . 8

Standards of Practice... . . . . . . . . 8

The Short Commercial . . . . . . . . . 10

Health Claims . . . . . . . . . . . . . 13

Federal Regulating Bodies... . . . . . . 13

Federal Trade Commission (FTC) . . . . . . 14

The Food and Drug Administration (FDA) . . 16

Controversy Surrounding Health Claims . . . . 17

Influence of Television Advertisements . . . . . 19

Advertisements for Target Audiences . . . . . 20

Obesity . . . . . . . . . . . . . . 20

Alcohol Consumption . . . . . . . . . . 23

Moderate Alcohol Consumption . . . . . . 24

Alcohol Abuse . . . . . . . . . . . . 24

Alcohol Consumption in Pregnancy . . . . 24

The Elderly . . . . . . . . . . . 25

Teenage Drinking... . . . . . . . 25

Non-Addicts .. . . . . . . . . . 27

Control Laws.............. . 28

The Children . . . . . . . . . . . 30

The Elderly . . . . . . . . . . . . 35

summary . . . . . . . . . . . . . . . . . 40

III. METHODS AND PROCEDURES . . . . . . . . . . . . . 41

Introduction . . . . . . . . . . . . . 41

Sampling Plan .. . . . . . . . . . . . . . 4l

Content Analysis . . . . . . . . . . . . . . . . 47

Verification of the Researcher's Perceptual

Reliability . . . . . . . . . . . . . 49 
The Proportion of Food and Nutrition

Advertisements $\cdot . \cdot \cdot \cdot \cdot \cdot \cdot \cdot . \cdot \cdot \cdot .51$

Proportion Calculated from this Sample .. . 51

Proportion Calculated from Johnny-on-the-spot 51

Inter-rater Reliability . . . . . . . . . . . 52

Likert Scale Correlations . . . . . . . . 52

Overall Correlations . . . . . . . . 52

Correlations for Each Scale . . . . . 54

Reliability for Presence and Accuracy of

Health Claims .......... . . . 60

Presence of Health Claims . . . . . 60

Accuracy of Health Claims . . . . . . 62

Discussion . . . . . . . . . . . 65

Content Analysis ................ 66

Proportion of Health claims . . . . . . . 66

Correlation Analysis of the Implied Messages

Scale . . . . . . . . . . . . . 66

Effect of Station Type . . . . . . . . . 67

Rationale for Eliminating Period 1

Advertisements ............. 67

Effect of Period of Day . . . . . . . . . 71

Effect of the Days of the Week . . . . . . 73

Effects of Food Class . . . . . . . . . . . . 73

Analysis of Saturday Morning/Afternoon Cereal and Snack Advertisements . . . . . . 84

Interaction Analyses . . . . . . . . . 85

Station Type by Period of Day . . . . . 85

Station Type by Day of Week . . . . . 85

Period of Day by Day of Week . . . . . . 90

Five Most Prevalent Food Classes by the

Day of the Week . . . . . . . . . 90

Discussion ................ . . 95

Frequency of Health claims . . . . . 95

Station Type . . . . . . . . . . . 95

Period of Day . . . . . . . . . . . . 95

Day of Week . . . . . . . . . . . . 96

Food Class . . . . . . . . . . . . 96

Station Type by Day of Week Interactions . 97

Period of Day by Day of Week Interactions 97

Summary of Results . . . . . . . . 97

v. SUMMARY, CONCLUSIONS AND RECOMMENDATIONS . . . 100

Summary and conclusions . . . . . . . . 100

Recommendations . . . . . . . . . . . 102

Future Research ... . . . . . . . . 103

IEFERENCES . . . . . . . . . . . . . . 104 
APPENDICES . . . . . . . . . . . . . . . . 109

A. Sampling Schedule . . . . . . . . . . 109

B. Sample Data Collection Sheet . . . . . . . . 111

c. Descriptor List for Implied Messages Scales . . 112

D. Instructions, Implied Messages Form (Likert Scales), and Health Claims Questionnaire. . . 117 
1. Correlation between the researcher's and panel's Likert scale responses for the Healthy scale . . 56

2. Correlation between the researcher's and panel's Likert scale responses for the scientific scale . . . . . . . . . . . . . . . .

3. Correlation between the researcher's and panel's Likert scale responses for the Fitness scale . 58

4. Correlation between the researcher's and panel's likert scale responses for the weight Control scale . . . . . . . . . . . . . . 59

5. Distribution of food advertisements over the days of the week . . . . . . . . . . . . . . 74

6. Interaction between the station type and the day of the week for the proportion of advertisements with a Healthy message . . . . . . . . . . 88

7. Interaction between the station type and the day of the week for the proportion of advertisements with a Weight Control message . . . . . . . 89

8. Interaction between the period of the day and the day of the week for the proportion of advertisements with a Weight Control message . . 92

9. Interaction between the station type and the day of the week for the proportion of advertisements with a health claim . . . . . 93

10. Distribution of the 5 most frequent food classes across the days of the week. . . . . . . . . 94 
1. Likert scales averaged over the 25 advertisements for both the researcher and the panel $:$. . .

2. Correlations between the researcher's and panel's responses for each Likert scale . . . . . . .

3. Detection of health claims by researcher and panel members

4. Researcher and panel member assessment of health claim accuracy . . . . . . . . . . . . .

5. Correlations among the Healthy, Scientific, Fitness, and Weight Control scales . . . . . . . .

6. Differences between types of stations for proportions of food advertisements with Healthy, scientific, Fitness, and Weight Control messages and health claims . . . . . . . . . . . . . . .

7. Number of food advertisements for each period of day and station type............... 70

8. Differences between periods of the day for proportions of food advertisements with Healthy, scientific, Fitness, and Weight control messages and health claims

9. Comparisons of days of the week for the proportions of food advertisements with Healthy, scientific, Fitness, and Weight Control messages and health claims.

10. Proportions of advertisements for seventeen food classes

11. Comparisons of 17 food classes for the proportion of advertisements with Healthy, Scientific, Fitness, and Weight Control messages and health claims . . . . . . . . . . . . . . .

12. Proportions of advertisements with Healthy messages for each food class

13. Proportions of advertisements with Scientific messages for each food class . . . . . . .

14. Proportions of advertisements with Fitness messages for each food class 
15. Proportions of advertisements with Weight Control messages for each food class..........

16. Proportions of advertisements with health claims for each food class . . . . . . . . . . .

17. Results of 2-way analyses of variance conducted to assess the interaction between station type and period of day for the proportion of advertisements with Healthy, Scientific, Fitness, and Weight Control messages and health claims.

18. Results of 2-way analyses of variance conducted to assess the interaction between station type and day of week for the proportion of advertisements with Healthy, Scientific, Fitness, and Weight control messages and health claims.......

19. Results of 2-way analyses of variance conducted to assess the interaction between period of day and day of week for the proportion of advertisements with Healthy, Scientific, Fitness, and Weight control messages and health claims . . . . .

20. Possible types of nutritional misconceptions or behaviors based on client viewing habits.... 


\section{ACKNOWLEDGEMENTS}

I wish to thank Katharine Curry, Ph.D., R.D. for her help in guiding this project as well as for all of her support and confidence. I also want to thank Nancy Wellman, Ph.D., R.D. and Susan Himburg, Ph.D., R.D. for their special efforts on my behalf.

I was fortunate to have Jim Lewis, a skilled and talented statistician, as a collaborator. I thank him for his friendship, the many hours he spent with me discussing this work, and for the professional courtesies he extended to me.

I also owe a great deal to my friend Eva-Lynn Steckbeck, for her constant encouragement and for keeping our business running while I spent time completing this thesis.

A very special thank-you goes to my wonderful husband, Jerry Bender, for always coming to my rescue when I needed him. 
Television (TV) reaches more people than any other medium which makes it an important source of health information. Since TV ads often offer information obliquely, this study investigated implied health messages found in food and nutrition TV ads. The goals were to determine the proportion of food and nutrition ads among all TV advertising and to use content analysis to identify their implied messages and health claims.

A randomly selected sample of $\mathrm{TV}$ ads were collected over a 28-day period beginning May 8, 1987. The sample contained 3547 ads; 725 (20\%) were food-related. All were analyzed. About 10\% of food-related TV ads contained a health claim.

Twenty-five representative ads of the 725 food ads were also reviewed by 10 dietitians to test the reliability of the instrument. Although the dietitians agreed upon whether a health claim existed in a televised food ad, their agreement was poor when evaluating the accuracy of the claim.

The number of food-related ads dropped significantly on Saturday, but the number of alcohol ads rose sharply on saturday and sunday. Snack ads were shown more often on Thursday, but snack commercials were also numerous on Saturday morning and afternoon, as were cereal ads. Ads for snack foods accounted for the greatest proportion of ads (20\%) while fast food accounted for only 7\%. Alcohol constituted about 98 of all food and nutrition ads. 


\section{STATEMENT OF THE PROBLEM}

\section{INTRODUCTION}

Television has a powerful influence on the lives of viewers. Research indicates that the content and the interpretation of a televised commercial message can affect a viewer's consumer behavior $(1,2)$. One author asserted that hidden or misleading statements in a commercial message may cause the viewer to desire, and ultimately buy, the advertised product (3). This is especially so where children are concerned, because they often will believe that the message is realistic and truthful (4). It is important for nutritionists, as health and nutrition educators, to take a serious look at the messages that people receive through the television medium (1) .

William Glasser, a psychiatrist, has linked many of his theories to the media, and especially to television. Glasser's writings attempt to show the many ways in which advertisers use implied messages to create perceived needs within the television viewer for a particular product (5). It has also been shown that repeated exposure to an advertised product will make that product more familiar to the viewer and will often lead to the purchase of that product (6). Glasser's theories inspired this study, and prompted the researcher to develop a tool to help nutrition consultants use knowledge of their 
clients' television viewing habits to understand potential nutritional misconceptions.

GOALS OF THE STUDY

There were two goals for this preliminary research. The first was to determine the proportion of food and nutrition advertisements among television advertising in the South Florida area. The second goal was to identify implied messages and health claims found in food and nutrition advertisements and to determine dietitians' perception of their accuracy.

\section{RESEARCH QUESTIONS}

1. Among a sample of South Florida television advertisements, what are the proportions and distribution of food and nutrition advertisements and related health claims?

2. What are the differences between network and independent stations for implied messages and health claims among food and nutrition advertisements?

3. What are the differences between saturday and the other days of the week for implied messages and health claims among food and nutrition advertisements?

4. What is the effect of time of day on the type of implied messages?

5. What is the frequency of health claims in food and nutrition advertisements?

6. What is the accuracy of the health claims? 


\section{DEFINITION OF TERMS}

Operational definitions associated with this study and the television industry are:

Broadcast Station: A station which broadcasts its program material for reception by an antenna. Cable companies may make broadcast stations available on their cable to allow the reception of material from distances outside of broadcasting ranges to give a better or a more consistent reception of a local broadcast station (7).

Cable station: A channel whose program material can only be seen when the viewer subscribes to a cable company (e.g., A\&E, MTV, USA, etc.) (7) .

Content Analysis: Any technique for making inferences by objectively and systematically identifying characteristics of messages $(8)$.

Independent station: A station which is not affiliated with one of the "Big Three" networks ( $A B C, C B S, N B C$ ). These stations determine all of their broadcasting content independently, and sell all of their advertising time independently (7) .

Network Station: A station which is affiliated with one of the "Big Three" networks. These stations determine some of their broadcasting content and sell some advertising time locally, but most of the programming is determined at the national network level. Presently, it is not possible to determine the difference between commercial messages aired nationally and those aired locally on network stations (7). 
CHAPTER II

RELATED IITERATURE

INTRODUCTION TO RELATED IITERATURE

Television advertising is a multi-billion dollar industry that is fiercely competitive (10). An all-out war exists between the cola companies while Kelloggs of Battle Creek, General Foods Corporation, General Mills Corporation, and Quaker oats Company fight for top sales in breakfast foods---and advertising is the vehicle to accomplish this goal $(11,12)$. Advertisers often attempt to entice consumers to buy their product through the use of seductive advertisements that are repeatedly aired at strategic times of the day and night and are designed to meet the wants of selected consumers $(13,14,15)$. Not only are advertisers competing among themselves, but the television stations are competing for the advertising dollars $(10,16)$. Companies choose to advertise in the hopes of larger profits (11).

Advertising can either serve to increase consumer awareness and knowledge or mislead the consumer into believing untruths to get them to buy a product at any cost (3). Health claims made in food and nutrition advertisements are quite common and have great impact on the consumer (3). The consumer is affected most when food and nutrition health claims involve issues regarding obesity, fitness and health, aging, childhood nutrition, and alcohol consumption. 
FINANCIAL ASPECTS OF TELEVISION ADVERTISING

To keep current, advertising sales executives subscribe to monthly reports such as JOHNNY-ON-THE-SPOT (17). This information was reviewed to determine how important advertising is to the television stations' income. The amount of money spent can be an indicator of the number of commercials to which consumers will be exposed. Such reports not only indicate the money spent by advertisers in all categories of television advertisements, but they also show the frequency with which various advertisements are aired (i.e., the number of "spots"). These reports are specific for particular viewing areas to increase their usefulness to the station (17).

Television advertising has changed over the years. In earlier years advertising agencies sought to reach a large, general (but measured) audience. This could be achieved by placing advertisements on the broadcast networks. To advertise on cable meant that the advertisers were chancing it with "a new programming medium that delivered an undefined, unmeasured audience" (14). Today there is not only competition between broadcast networks and cable stations for advertising dollars, but the cable stations vie for advertisers among themselves (13). It has been noted that advertising-supported cable TV evolved into two distinct media, "one adhering to broadcast-like qualities and the other fulfilling cable's original promise of appealing to diverse, highly segmented audiences" (16). 
Advertisers, aware of the strength of the television media, are allocating larger budgets to television advertising each year. The May 19, 1984 Economist revealed that the television broadcast networks would receive approximately seven billion dollars ( $\$ 7$ billion) in advertising revenues. Cable stations were expected to receive in excess of two hundred fifty million ( $\$ 250$ million) from advertising (10).

To gain a larger share of the advertising dollar, cable stations gather detailed statistics about the audience in their viewing area. They then by-pass the advertising agencies to present the statistical information directly to potential clients (10). Moreover, to woo advertisers, cable stations offer an environment for the advertisement directed at viewers who are most likely to purchase the advertised product; they even will offer exclusivity to the advertiser. When lower advertising costs, reasonable financial arrangements, and control over the show's content are added to the mix, a perfect marriage between the advertiser and the cable station results (13). With such benefits, the advertiser can create an emotional bond between the brand and audience $(13-15)$. There are numerous innovative techniques and strategies that can be used to assess cable audiences and, thus offer insight into the dimensions of cable viewing. By using these techniques and strategies, advertiser's estimates of the cable audience are more accurate (14). 
In 1983, cable's biggest advertisers were: (a) AnheuserBusch Cos., Inc. ( $\$ 13.6$ million); (b) General Foods Corp. ( $\$ 8.6$ million); and (c) General Mills, Inc. (\$6.3 million) (15). In 1985, according to Leading National Advertisers, "General Foods Corp. spent about $\$ 100$ million in spot TV and $\$ 200$ million in network TV" (16). The following figures were reported for 1986 in the 1987 standard Directory of Advertisers (18). The Kelloggs Company showed sales of $\$ 2,930,000,000$ with expenditures for television advertising dispersed as follows: $\$ 156,431,000$ for network television; $\$ 59,795,000$ for spot and cable advertisements. General Foods reported sales of $\$ 9,022,418,000$ with $\$ 500,000,000$ going toward all media advertising. The coca-Cola company had revenues of $\$ 7,903,904,000$ and television advertising costs of $\$ 195,271,000$ while Pepsico reported a sales figure of $\$ 8,056,662,000$ and television advertising costs of $\$ 270,191,000$. Seagrams wine spent $\$ 15,639,000$ on network television, $\$ 9,352,000$ on spot television, and $\$ 769,000$ on cable television advertising. No sales figures were given (18) .

It was expected that in 1987, even greater amounts would be budgeted for television advertisements (16). In 1987, General Foods Corp. expected to concentrate on local television advertising to build brand shares in retailers' markets (16). 
STATUS OF DECISION MAKING

Standards of practice

The "Big Three" (NBC, CBS \& $A B C$ ) operate wellestablished, well-staffed standards and practices divisions at the national level (1). Moreover, all of the Big Three publish advertising standards and practices manuals, freely provided to inquiring ad agencies and members of the public or press. Network stations at the local level and independent stations, however, have no such reference documents (1). Who, then, makes the final decisions about accepting or rejecting particular advertisements?

A survey run by Cable Age reports that the vast majority of advertiser-supported satellite networks "police their advertising on a decidedly ad hoc basis, with the ad sales department itself doing whatever policing is done" (1). Most satellites say that they follow advertising standards and practices fairly close to the major broadcast networks' where matters of taste and subject matter are concerned. "But few routinely practice a policy that requires a trained standards and practices official to screen all spots, examine all claims" (1). Most satellites admit that if it runs on the broadcast networks, it is good enough for them (1).

Per-inquiry [PI] advertisements are scrutinized much more closely. PIs are television's equivalent to mail order, and officials say they pose the most problems concerning advertising claims (1). Control by the television station is limited with PIs. Since advertisements may often be 
deceptive or misleading, or if the product is never delivered to the consumer, an irate viewer/consumer may then try to blame the television station (2). "But even in the case of PIs, it is standard procedure at some shops to depend on the ad sales staff" (1).

The one exception to the loose policing policies exists at one of the most financially embattled independent stations, Lifetime [LIF], formerly Cable Health Network [CHN]. LIF is the only independent station in the United states to employ a full-time person whose job is to evaluate the content of commercials before they are accepted for telecast. LIF's policies are especially conservative regarding health-related products. LIF rejects approximately 40 to 50 percent of all PI spots, most of which are health and diet related, because of ridiculous claims (1). Andy Feinstein, LIF's Vice President of Advertising Sales, states, "We have more of a responsibility than to say we'll put on anything the (broadcast) network approves" (1).

The Federal Trade Commission [FTC] only concerns itself with bringing actions that affect the greatest mass of consumers. Therefore, although they monitor for "false" or "deceptive" advertising, they most often focus their attention on the networks and "hot" independent cable stations. Also, when "false" or "deceptive" advertisements are identified, liabilities usually flow to the advertiser or advertising agency, not to the station transmitting the message ( 1 ). 
The National Advertising Division of the Council of Better Business Bureaus, Inc. [NAD] monitors advertisements on both network and independent stations. They adjudicate complaints from competing advertisers as well as the public on a voluntary compliance basis. The NAD rarely cites local network or independent advertisements. "Like the FTC, it focuses its attention on nationally broadcast network television" (1).

Local network and independent programmers have not gone the standards and practice route because of cost and attitude. Cable stations are just now beginning to make money, and they are fighting for every advertising dollar. Cable executives believe that since their operations are transmitted by cable television, they should not be subject to the same legal and regulatory constraints on advertising as the broadcast stations (1).

Charles Hanson, Jr., General Sales Manager for WPTV 5 (a local network station in West Palm Beach, Florida) stated, during a personal interview, that since advertising sales persons have no knowledge of standards and practices policies, a manual should be written for both internal and external use (2).

\section{The Short Commercial}

Herbert Krugman has extensively studied the advertising phenomenon of consumer "recall" and "recognition" (19). He believes that the right-brain hemisphere can process and 
store much more information than can be detected by standard recall measures, since the right-brain information is pictorial and recall methods are essentially verbal. This picture-taking ability of the right brain helps direct the focus of the left brain. He has shown that in General Electric television commercials aired from 1971 to 1980 , advertisements were most effective in shows that had continuity in format, such as dramas, but did less well in shows broken up by acts, such as variety or talk shows (19). If a viewer has paid close attention to an advertisement, then the effect of the advertisement can be easily measured with verbal recall. However, rarely does a viewer attend so closely to an advertisement. Krugman contends that the viewer is affected and points to the effectiveness of shorter and more numerous advertisements to support his argument (19) .

The advertising industry has found that short commercials ( 30 seconds or less) can be effective as compared with 60-second versions. The compressed speech of a 30second commercial will increase communication effectiveness and will decrease the length of the advertisement without a loss in understanding. Lately there has been discussion, both pro and con, about shortening commercials even further to 15 or 10 seconds (19).

Today, with the cost of television production and air time becoming so prohibitive, alternate media such as radio and print are beginning to be favored by advertisers. To 
continue using the television medium, advertisers are seriously considering shortening commercials to 15-seconds. Advertisers don't believe they can do a better job with the 15's, they just think that they can get by with shorter, less costly advertisements (20).

Hanson at Channel 5 commented that, "There is a limit! Too many ads in a very short span of time would only serve to create clutter, and would make the viewers angry" (2). When the National Association of Broadcasters [NAB] regulated commercials, they used a "Code of Good Practices" to screen all commercials before they could be aired (21). The frequency and the length of an advertisement also came under the NAB domain (2). According to Hanson, "In the old days, only 16 minutes out of every hour could constitute advertising minutes" (2). Wolfmueller (7) substantiated Hanson's statement. However, the NAB lost control and the "Code of Good Practices" was abandoned in 1982. A Federal court had struck down its guidelines on antitrust grounds $(1,2)$. Today, most stations still adhere fairly closely to 16 minutes of advertisement for every hour of telecast time $(2,7)$.

In the April 1967 Media/Scope, Schwerin said that it is easy to lose one-half the audience or more in the first 16 seconds of commercial time. His research concluded that the opening sequence of any commercial is of key importance, "since advertisers must capture and hold the attention of viewers to retard them from mentally or physically tuning 
out" (22). This makes advertising placement critical! The advertisement shown first in a string of commercials will most probably be the one that gets seen by the viewer; this happens because of the high rate of "zapping" (switching channels) during commercial messages. A survey by A.C. Nielsen demonstrated that between 5 to 7 percent of the average prime-time audience switch channels during commercial minutes (9). Advertisers realize this, and argue for the use of the short commercial in order to hold a "captive" audience. Under captive conditions with repeated exposure, recognition memory exists even though the minimal cues and messages received by the viewer from a short commercial will decrease the viewer's ability to recall the exact message. The recognition memory will, however, leave some faint impression which will, in turn, produce a sense of familiarity with objects, brands, and/or messages. This is important because people usually select those products with which they are most familiar (19).

\section{HEALTH CLAIMS}

Federal Regulating Bodies

The Consumer Product Safety Commission, the Food and Drug Administration [FDA], the Federal Trade Commission [FTC], the Environmental Protection Agency, the Department of Agriculture, the Department of Transportation, the Federal Communications Commission, the Department of Housing and Urban Development, the Interstate Commerce Commission, the 
Federal Reserve System, and the Securities and Exchange Commission are federal agencies that issue rules and regulations to achieve consumer protection (23). The FTC is the regulating body most directly involved with television advertising. The FDA will be mentioned briefly. Although the FDA regulates food and drug products and labeling, decisions made by this regulating body also have a bearing on decisions made by the FTC.

Federal Trade Commission [FTC]: The FTC acts as an independent law enforcement agency which was created by Congress to protect the public against anti-competitive behavior and unfair and deceptive business practices (23). The FTC defines practices that violate the law, thus marketers can be provided with advance knowledge of their legal obligations and the definitions enable consumers to recognize those business practices against which legal recourse is available (23).

The FTC came into being in 1914 as a result of the Federal Trade Commission Act. It was originally up to the FTC and the courts to define that which constituted an unfair practice. Additional legal responsibilities for consumer protection were delegated to the FTC over the years (23). The FTC has five specialized divisions: Compliance, Marketing Practices, National Advertising, Special Projects, and special statutes. The provisions of the FTC Act directed at preventing misrepresentation and unfairness in all national advertising is enforced by the National Advertising 
Division. This division is particularly concerned with food, drug, and cosmetic advertising (23).

Until 1969 the FTC was known as the "little old lady of Pennsylvania Avenue"---consumer activists were complaining that the agency was not fulfilling its responsibility of protecting consumers from unfair or deceptive marketing practices. Nader, in 1968, and the American Bar Association $(A B A)$, in 1969, leveled criticisms at the FTC. Following investigations by Nader and the ABA, the FTC began to change in late 1969. In 1970, Weinberger was appointed chairman of the FTC, and he changed several policies to provide greater consumer protection within the commission. His work was continued by Kirkpatrick, who had headed the $A B A$ study group (23). "In 1971 Nader remarked that 'the FTC is waking up to its responsibilities which is attributable to a new and more vigilant staff."" (23)

In 1982, Miller, Chairman of the FTC, proposed sweeping changes in the scope of the FTC's regulation of advertising (24). These proposed changes would ultimately limit FTC authority in the area of food and drug advertising (25). The Reagan Administration's deregulation thrust has led to considerable discussion, hearings, and research into a fundamental public policy issue, "the social benefits and costs of regulating advertising" (24). The proposed changes can have "severe and far reaching social and public policy implications" (24). The Miller proposals would cause a reversal in consumer protection to earlier standards. Where 
advertising is concerned, the Miller proposals would "effectively return the U.S. market to the 19th century principle of caveat emptor" (24). In 1982, the FTC's separate food and drug advertising unit was closed and the commission abandoned efforts to control food advertising (26).

The Food $\&$ Drug Administration [FDA]: The FDA has been slow to allow health claims on food labels, but in 1985 many rulings were relaxed $(27,28)$. Frequently, FDA rulings influence subsequent decisions and rulings by the FTC. A 1985 article in Advertising Age stated that a committee was formed to develop a "policy on what food marketers should not do as well as on FDA enforcement of health claims" (27). The committee was chaired by the FDA commissioner and included representatives of the FTC and various offices of the Public Health Service (27).

The American Cancer Society [ACS] added diet to cigarette smoking as "key planks in its anticancer platform" (29). The ACS decision "should enlarge the growing pool of consumers whose food-buying decisions are influenced by health concerns" (29). Since regulatory constraints regarding health claims in advertising are becoming more relaxed, food marketers are adding health claims to advertised messages. However, the ACS is leery to endorse food advertisements with diet tie-ins (29).

Although the manufacturers of artificial creamers, cookies, crackers, etc. spend billions both in magazines and 
on television, and use famous actors to praise their "no cholesterol" products, they fail to mention that many of these products contain large amounts of saturated fat. The Center for science in the Public Interest cites this as an example of one of the major deceptions (30).

Controversy Surrounding Health claims

Since 1982, renewed controversy has centered around the issue of health claims in food and nutrition advertising. According to FTC Consumer Protection Bureau Director Crawford, "health and nutrition ad claims are coming under close scrutiny in a rekindled effort at the FTC to police food advertising" (26).

Herbert, a physician (3), has written widely on the danger of making health claims for specific foods or supplements. To do so may lead consumers to use the foods or supplements to excess and away from considering their entire diet. The claims may state literal truths, but send false messages. "The consumer is deprived of informed choice when relevant information is withheld, whether it is withheld by intent or by ignorance" (3).

Schroeder, Senior Vice President-Administration, General Foods Corporation took the opposite viewpoint. He recognized that the subject of health claims is one of the most important issues facing the food industry today. He claimed that "General Foods has been a leader in providing nutrition information on our food products for over 15 years" (31). He 
pointed out that they provide not only the specific health claims associated with their products, but also general information to help the consumers understand nutrition. "Our overriding theme has been that it is how we mix and match our foods that makes for good nutrition---in other words balance, variety and moderation" (3I).

He further stated that General Foods as well as many other companies have worked to build public trust and accuracy in advertising. To insure that trust and accuracy, caution through substantiation should be the path when making health claims. However, he said that "it is just as difficult to get complete agreement on matters of health and nutrition as it is with any other complex topic" (31). For example, when General Foods was not able to find a unanimous view from scientists on the relationship between dietary fats, cholesterol and heart disease, they stated in their advertisement that "there is genuine uncertainty about the relationship between diet and heart disease" (31). They specifically mentioned the variability in individuals' responses to dietary fat and cholesterol. They stated that they will not base their specific health claims on "mere hypothesis or on bare majority of votes among the scientists. It is the quality of the scientific agreement that is of interest to us rather than any numbers game" (31).

According to an Advertising Age editorial, the Kellogg Company of Battle creek is capitalizing on their new-found ability to make health claims in order to "push" 'All-Bran' 
cereal (32). Kellogg "all but created Saturday morning kids' T.V. with their cast commercials on the wild Bill Hickcock Show and their block booking of this time slot" (20). In more recent years, Kellogg has participated in controversial health claims which have been both praised and scrutinized by the National Cancer Institute, FDA, and FTC (20).

\section{INFLUENCE OF TELEVISION ADVERTISEMENTS}

The "identity society," a term coined by psychiatrist Glasser, refers to the recent occurrence of Western man's struggle for recognition and fulfillment as a human being. The term goes beyond man's basic needs for survival and security to more advanced needs for quality of life, recognition and pleasure (5). Glasser identified these advanced emotional needs as: 1) love and a sense of belonging or involvement; 2) control over one's own life and a feeling of importance; 3) having fun; and 4) being free. Humans constantly strive to have these needs met. once met, we rest for a while and then seek increased fulfillment for these emotional needs (33).

Glasser sees the media, especially television, as a final force in "causing the emergence of the identity society" (5). He claimed that since the 1950's television has become very influential in our lives and that we have become dependent upon television for evening and weekend entertainment. Children have typically watched over 2,000 hours of television before they enter school. Television's 
influence is still spreading, and has influenced the lives of almost everyone in the Western world. Some of the consistent messages, from both programs and advertisements, are the importance of personal worth and pleasure, dissatisfaction with the status quo, and achievement of human potential. It is implied that people can "best achieve their own human potential by using the various products advertised or by living like the people shown in the programs" (5).

ADVERTISEMENTS FOR TARGET AUDIENCES

The implied messages that a person may receive through a television advertisement may reinforce negative addictions to food, alcohol or drugs. The following sections will be directed toward specific target audiences who may be influenced to a great degree by television advertising of food.

Obesity

Glasser comments that food is "potentially addicting because eating provides pleasure and that pleasure can be regained easily just by eating more" (33). Most people control their food intake at some reasonable level in order to "feel worthwhile when they look in a mirror" (33). Today's fashion dictates a "too-thin look" which prompts a continual struggle for some.

Obesity is associated with many health hazards (34). A 1985 National Institute of Health Consensus Development 
Conference concluded that "evidence is overwhelming that obesity, defined as excessive storage of energy in the form of fat, has adverse effects on health and longevity" (35). These adverse effects include hypertension, Type II (maturity onset) diabetes, hypercholesterolemia, and excess of certain cancers, problems, and a decreased life span (35).

"Beyond all these hazards is the risk incurred by millions of obese people throughout much of their lives---the risk of ill-advised, misguided dieting" (34). The "battle of the bulge" is a problem that has plagued Americans for many years. Unfortunately, the quest for the "ideal" body has left the door open for many unscrupulous advertisers to capitalize on the vulnerability of a public that is frantically seeking the newest, most painless, and easiest way to shed extra pounds---and keep them off. "Billions of dollars are spent each year by individuals struggling to lose unhealthy excess weight" (36). Most people are "acutely aware of the dangers of excess body weight," but the "actual risks posed by obesity are limited to some $20 \%$ of the American population" (36). It is estimated that more than $50 \%$ of the population are driven to diet, and the cause comes from sociocultural norms and advertising linked to thinness (36).

However, there is a widening gap between what we would like to be and what we are. "We are increasingly a nation of broad bottoms and bulging middles" (37). The National Center for Health statistics has confirmed "that the total population has gotten plumper over the last 20 years"(37). 
The average adult was 6 pounds heavier in 1980 than he or she was in the 1960's (37). Adams and Trachtenberg, in Forbes magazine, say that all of this is due to a fast-food frenzy. According to them, "We don't have to hunt food any more. It hunts us" (37).

Fast food hardly existed 10 years ago, and represents a dramatic change in our society. At one time, meals eaten at home were rituals. Today every third meal is eaten outside the home. McDonald's institutionalized the trend with their marketing techniques and advertising. McDonald's has become a happening and advertising in this category has become a part of the times (32).

It has been estimated that "97\% of American homes have a television set that is on almost 7 hours a day," and food and drink "are the largest single category of advertising on television and represent about $70 \%$ of total T.V. advertising spending" (37). One reason that McDonald's is so successful is because they represent a large part of that 70 percent. We are bombarded with advertisements for food! (37)

External stimuli cause some obese people to overeat. Instead of responding only to internal, visceral hunger cues, "they seem to respond helplessly to such external factors as the time of day ('It's time to eat') or the availability, sight, and taste of food" (34).

Falciglia and Gussow investigated the probability that televised food advertisements act as external cues for eating. The obese "were clearly more responsive than normal- 
weight individuals to television food commercials as an eating cue," and "under certain circumstances, television may function as a highly salient external stimulus to food consumption" (38). With the pervasiveness of television, the high percentage of food advertisements shown, and the apparent vulnerability of the obese to external food and related cues, television food and drink advertisements may contribute to excessive caloric intake in the obese (38).

Whitney and Hamilton believe "the implications for treatment of obesity are obvious" (34). Recommended strategies include avoiding places where the 'eat me' signals from food are too overwhelming. Next, obese people need to "create environments for themselves where food stimuli are at a minimum, and to learn to say no in circumstances where tempting but unneeded foods are offered" (34). The environment of the 1980 s is not conducive to weight control. The same television station that will "display the slim athletic bodies of male and female models" will also air commercials that offer "mountains of delectable, technicolor food in its commercials" (34).

\section{Alcohol Consumption}

Alcoholic beverages, America's "drug of choice" provide relaxation, and facilitate social interaction $(5,34)$. Moderate alcohol use by non-addicts can be pleasurable and is not necessarily tied to the relief of emotional pain as it so often is with alcohol abusers (5). 
Moderate Alcohol Consumption: The term moderation depends upon the individual's ability to tolerate alcohol. As a general guideline, three drinks or less are considered a moderate intake for the average-size, healthy male; two drinks or less for the average-size, healthy female. "This amount is supposed to be enough to produce euphoria without incurring any long-term harm to health" (34). Some benefits of moderate alcohol use include reduction of stress to improved appetite to improved cardiovascular mortality (34). Alcohol Abuse: "More than 90 percent of the people who drink have no serious problem with alcohol," but "some estimate that there are 10 million alcoholics in the USA alone" (39). Excessive use of alcohol can have devastating effects including death or injury via auto accidents, illnesses with astronomical medical costs, destruction from fires, and social services for alcoholics (40). An important negative effect of alcohol abuse is its effect on the person's nutritional status (34).

\section{Alcohol Consumption in Pregnancy: Fetal alcohol} syndrome results in irreversible brain damage and mental and physical retardation in the newborn. It is caused by excessive alcohol intake by the pregnant female. Often the most severe "impact is likely to be in the first month, before the woman even is sure she is pregnant. About 1 in every 750 children born in the United states is a victim of this preventable damage" (34). 
The Elderly: "A recent estimate sets the incidence of alcoholism in people over 60 in our society at 2 to 10 percent" (34). Alcohol use has its most profound effects on thiamin, and folacin, calcium and zinc, but affects nearly every nutrient to some extent (34). This can be a problem if the older person's nutritional status has already been compromised. "Where it is a problem in elderly people, it must be recognized before it can be dealt with" (34).

Teenage Drinking: Teens are exposed to experiences not encountered before; alcohol is one of the new experiences. since the teens are still in a period of growth, nutrient needs are still quite high. Alcohol, an empty-calorie beverage, can displace needed nutrients from the diet of teens while simultaneously altering metabolism so that even good nutrition cannot normalize it (34).

Former Surgeon-General Richmond stated that reduced television advertising lessened the incidence of smoking in the United States. Television could help reduce alcohol consumption by: 1) reducing the number of advertisements for alcoholic beverages, and 2) not portraying alcohol consumption in a positive manner on television programs (41). Singer examined the alcohol use of young people and their television viewing habits. She claims that although advertising of liquor on television is prohibited, it hardly seems worthwhile. There are a large number of wine and beer advertisements on television. "A total of $\$ 411$ million was spent on national media advertising of alcohol in 1977; the 
largest portion for beer (48\%, mostly on television)" (42). Network television showed 5,000 beer and 600 wine advertisements in 1977, and they were "mostly aired during weekend sports and prime-time evening shows" (42).

singer cited a survey by Atkin of 1,227 respondents, 12 to 22 years. The study "suggests that a number of negative effects can be traced back to alcohol advertising" (42). The Atkin study revealed that more attention was paid to television than magazine advertisements for beer and wine. The primary audiences were high school students and recent graduates. The advertisements positively portrayed drinkers' personalities and social benefits. Thirty-two percent of those with high exposure to these advertisements agreed that it is acceptable for teenagers to drink, while only $20 \%$ of the low exposure group had this opinion.

Tucker studied the amount of time 394 teenage males watched television and their alcohol use. The teens were classified as light, moderate, or heavy television viewers. "Heavy viewers consumed alcohol significantly more often than did light and moderate viewers" (43). Although this study was concerned primarily with alcohol-related messages seen within the context of the program, television advertising of alcohol is thought to be positively correlated with teenage acceptance of alcohol use (43).

Atkin, Hocking, and Block surveyed 665 teens in grades 7-12 in Michigan, California, New York and Georgia about 
their drinking behavior, exposure to alcohol advertising, and other possible communication influences (44). The results showed that exposure to alcohol advertising is significantly associated with drinking behavior and intentions. It is suggested "that ads appeal to young people because the messages stress their desired goals, such as good times, sex and social acceptance" (44).

Non-Addicts: According to Wallack, Breed, and Cruz, "advertising and television programming are seen as important contributory forces to the social environment in which drinking and alcohol-related problems occur" (45). Both advertising and television programming have been criticized for portraying an image of alcohol that is inconsistent "with the reality of alcohol as a major public health problem" (45). Alcohol consumption is associated with the loss of 80,000 to 200,000 lives each year and costs society approximately $\$ 120$ billion annually (45).

since numerous alcoholic beverage advertisements appear on television, the possible effects have been hotly debated. The alcoholic beverage industry claims that "they do not design their advertising to convince people to drink more. Rather the companies say that they are trying to increase their individual shares in an existing market" (46).

Sobell examined the drinking behavior of 96 male normal drinking college students (47). The students were assessed after they viewed a videotape of a popular prime-time television program complete with advertisements. The results 
gave no support "that drinking scenes in television programs or televised advertisements for alcoholic beverages precipitate increased drinking by viewers" (47).

Control Laws: Ornstein and Hanssens tested the social marketing effectiveness of alcohol control laws designed to reduce the consumption of alcoholic beverages. Through historical data used to measure the demand for distilled spirits and beer, and using economic, sociodemographic, and control-law explanatory variables, it was found that "control laws affecting price have the greatest impact on consumption. In the case of beer, the primary influence on demand is the youthfulness of the population" (40). In contrast, the control measures as a variable had a small effect on consumers' overall attitudes toward drinking (40).

The Board of Trustees Report, American Medical Association, stated "there have been no federal prohibitions against alcohol advertising since the repeal of Prohibition in 1933" (48). Of two agencies with jurisdiction in this area---the Federal Trade Commission (FTC) "has no regulations that apply exclusively to alcohol advertising, but does subject such advertising to the same 'unfair and deceptive' standard it applies to all advertising" (48). The center for Science in the Public Interest, twenty-eight other organizations, and three individuals, filed a petition with the FTC in 1985. They argued that in those cases where alcoholic beverage advertising and promotion practices do not actually misrepresent the attributes of alcoholic beverages, 
some practices are "deceptive and/or unfair because they portray alcoholic beverage consumption and/or abuse in an appealing manner" (48). The petition contended that increased consumption and alcohol abuse could result from such advertising and marketing practices (48).

In response to the petition, "the FTC pledged to continue an ongoing review of alcohol advertising and marketing practices to identify any that warrant challenge as deceptive or unfair" (48). But requests for rule-making, industry-wide investigation of the problem, and enforcement actions to challenge the legality of specific advertising campaigns was denied (48).

Much available research supports the conclusion that "increased levels of alcohol consumption can be correlated with a higher prevalence of alcohol-related problems" (48). The AMA Board of Trustees reviewed existing data on the extent of alcohol abuse and the "influence of advertising and promotional practices on patterns and extent of alcoholic beverage consumption" (48). They reported that the evidence for a causal link between advertising and alcohol abuse is inconclusive (48). However, they expressed deep concern about the extent of alcohol abuse in American society today and the use of alcohol by young people and pregnant women.

The AMA Board recommended that more research should be conducted to provide more definitive evidence on whether advertising contributes to alcohol abuse, and if so, in what manner. The alcoholic beverage industry should discontinue 
advertising directed toward youth, such as promotions on high school and college campuses. Advertisers and broadcasters should cooperate to eliminate television programs that portray the irresponsible use of alcohol without showing the adverse consequences. All alcoholic beverage containers should have health education labels and all alcoholic beverage advertising should use such health education information. The AMA should "encourage the alcoholic beverage industry to accurately label all product containers as to ingredients, preservatives, and ethanol content."

The Children

Glasser stated that children who know nothing other than the identity society and who also spend much of their time watching television "get constant reinforcement that they are important, that they are valuable, and that they should lead the good life" (5). Radio, magazines, and newspapers exert influence on people; however, "television, because of its nature and because of the time involved, has a greater influence on people, especially the young and impressionable, than any of the other media" (5).

According to stoneman and Brody, there has been much controversy regarding the ways in which television food advertising affects children, but they say "there is a dearth of knowledge concerning the processes through which television advertisements impact children's food preferences and eating habits" (49). They studied how peer-modeled food 
preferences combined with television food commercials influenced the food preferences of school-aged children. They found that peer food preferences and televised food advertisements presenting similar information can function as additive sources of influence. The social influence effects were strongest "when peers modeled food preferences that were in agreement with the products presented in the television commercials" (49). The children watched only one peer demonstrate food preferences, but it is "probable that the peer's choices were interpreted by the viewing child as representing the preference of the child's larger peer group" (49). They also found that children are not passive recipients of food messages. It is an active process where the information is received and then "a decision-making process will determine whether or not the advertised message will affect the child's behavior" (49).

Many children spend more time in front of the television than in the classroom. The average American child aged 2 through 11 years watches almost 4 hours of television daily and more than 20,000 television commercials annually (50). Barcus estimated that 1 out of every 5 hours of a child's television viewing are commercial messages designed to influence consumer behavior (51).

Gussow found that of the 20,000 commercials children watch annually, between 25 and 50 percent are for food products high in sugar, fat, and calories (52). Galst and White reported that saturday morning commercials on 
children's television programs included the majority (approximately 80\%) "evenly divided among four product categories---toys, cereals, candy/sweets, and other food/snacks---each with about $20 \%$ of the total" (53).

Barcus found that one in four food commercials are for sugared cereals and that they "outnumbered those for unsugared cereals by three to one during both weekend and after-school programming directed at children" (54). Studies have shown a positive relationship between the amount of time a child watches television and the child's consumption of heavily advertised foods $(53,54)$. Overconsumption of sugared and high-calorie/high-fat foods can lead to tooth decay, obesity, and other health problems. Critics maintain that television advertising for these products can adversely affect children $(34,55)$.

According to Whitney and Hamilton, children gain a lot of information about foods from television sets. They state that "authorities are concerned that television commercials may have a less-than-desirable impact" (34). They also state that the average child who sees more than 10,000 commercials each year, are exposed to more than 5,000 advertisements for sugary foods. "Hundreds of millions of dollars are spent in the effort to sell these foods to children," and most of the concern is centered on the issue of sugar (34).

In 1972 Gussow analyzed food products advertised on saturday morning television on $A B C, C B S$, and NBC. Breakfast cereals comprised $38.5 \%$ of the sample, and snacks such as 
cookies, candy, gum and popcorn made up 17.0\%. The remainder of the commercials advertised such products as beverages, frozen and canned foods, and vitamins (no longer advertised).

In 1978 and 1979, the FTC held hearings on regulating children's advertising. In response to the request for comments, the FTC received about 10,000 letters from consumers. The major issues of concern were the potential effects on: 1) children's nutritional behavior and knowledge due to the types of products advertised; 2) parent-child relations; 3 ) concern over children's abilities to distinguish programs from commercial content and to comprehend the selling intent of the advertisements;

4) deception created by particular production techniques; and 5) problems with certain selling techniques (e.g. host selling and premium offers) (56).

Consumers supported banning advertisements of heavily sugared products, supplementing advertisements, and banning all television advertisements to younger children (56). Dietz and Gortmaker found "that television viewing was significantly associated with obesity, particularly in children aged 12 to 17 years" (57). Ten percent of teenagers who watched up to 1 hour of television daily were defined as obese, but more than 20 percent of those who watched more than 5 hours daily were classified as obese (57).

Research suggests that if a child believes an advertisement is true and accurate, then his attitude and behavior are likely to be consistent with the advertised 
message $(58,59,60)$. Age acts as a determinant for children's behavior in relationship to advertising and their understanding of the selling intent and truthfulness of commercials. Children who are less than 8 years of age usually believe that advertisements are true. The younger child is also more likely to ask for the advertised product $(58,59,60)$.

Sprafkin, Gadow, and Dussault attempted to measure children's perceptions of the reality of television programs and commercials (61). Since handicapped children watch even more television than their nonhandicapped peers, one goal of the study was to compare the performance of emotionally disturbed [ED] children to nonhandicapped children on perceived television reality. The results indicated that school-identified ED children are more likely to see television programs and commercials as reality than are their nonhandicapped peers (61). These perceptions "make them more like younger children who do not understand the selling intent of commercials" (33).

Children are naive and vulnerable consumers, according to Palmer and McDowell, and "food advertising to children and questions of health and nutrition" continue to be central issues (62). Their study examined understanding of commercial network techniques---both audio and video--designed to communicate the "balanced breakfast" concept. They found a general lack of concept understanding (62). 
The researchers questioned whether a child's concept of "balanced", "big", "good", or "right kind" of breakfast might differ from the breakfast they normally have? Each child in the study was individually interviewed regarding the content of their breakfast and their reasons for eating the foods reported. Data were recorded by food groups, and the usual breakfast pattern was compared with media-terminology breakfast patterns. It was revealed that a child's usual breakfast paralleled the "good" breakfast and significantly differed from a "big" breakfast. "Taste, authority, and health (in that rank-order) accounted for 96 percent of the reasons children gave for their breakfast-eating behaviors" (62). Taste accounted for 42 percent of the reasons, and 30 percent were authority-related reasons. Twenty-four percent of the reasons given were health-related while hunger accounted for 4 percent of diverse responses (62).

\section{The Elderly}

Elderly people comprise a growing population of active consumers who are looked upon by marketers as a viable market $(63,64)$. Increasingly larger numbers of advertisers are interested in this group since the proportion of older people within the general population continues to expand (63).

older people tend to watch more television than any other age group. Thus, they are more exposed to television advertising (63). Older individuals who gather information from the television set often, are homebound as a result of 
rural location, lack of transportation, or physical disability. Older people are often timid or may be embarrassed to participate in a group situations. "Methods tested for reaching older people at home have included oneto-one visitation and the mass medial (65).

As age increases, health problems increase. Food misinformation is a problem among older people. They are particularly vulnerable to products that advertise cures for well-known chronic complaints that cannot be healed by available medicines. Health maintenance is another concern for the older person. Attempts at keeping well may seem less threatening and costly with patent medicines or vitamin supplements than visits to a physician. Such decisions may postpone necessary treatment for the health problem. Another danger of food misinformation comes from the detrimental effect on nutrient intake resulting from avoidance of foods or categories of foods thought to be harmful to health (65). The older individual is easily misled by incomplete or inaccurate statements made by food advertisers. They "come under the Federal Trade Commission's definition of a 'special audience' (one which has special needs for information and for protection against deception)" (63).

clancy examined the effects of television viewing and exposure to television advertisements on elderly people. It was found that "food habits of the elderly are related to television viewing" (63). Since the nutrient intake of many older people is not optimum, "any attempt at changing food 
habits should be in the direction of encouraging more, not less, nutritious food" (63). Television advertisements, therefore, should be more closely monitored to insure accuracy, especially where the advertisements are making health claims for food products.

Fraud and quackery have been repeatedly pointed out as a critical consumer problem of older people (64). older people are vulnerable for many social and psychological reasons including: Low income, lack of education, desire for security and stability, helplessness, loneliness, grief, lack of feedback from trusted information sources, suggestibility, and desire for health and avoidance of pain (64). However, a study by Schutz, Baird, and Hawkes does not support the popular view of the elderly as more frequent victims of fraud and deception (64). In fact, age actually had "a negative relationship to the factor 'disappointing consumer experiences' and no relationship to 'consumer problems'" (64). Most older people reported being disappointed with "faulty performance, repair and service problems, financial transactions, and advertising" (64).

With an increased incidence of illness as one ages, health-related dietary restrictions often become a necessity. The older person must seek out and buy food products that will comply with dietary restrictions and will adequately meet his needs. Foods must often be of the convenience-type for ease of storage and preparation; at the same time price is usually a significant factor (64). 
Women over 65 have been found to be "slightly more concerned about nutrition than younger women are, most likely a result of age related health concerns" (64). Younger men are more interested in cooking than men over 65 (64). Men over 65 are not as concerned about nutrition as older women, but they are more concerned than younger men about salt, cholesterol, and weight control (64).

Schutz, Baird and Hawkes also reported that monthly food expenditure was the only behavior related to increasing age or to income (64). Other behaviors were related to lifestyle factors. Seventy-five percent of those studied were directly involved in shopping for their own food and had definite reasons for their choices. More than 50 percent shopped on a regular basis for specials, and they compared prices, weights, volumes, and ingredients when purchasing packaged goods. Only 33 percent reported that they stay with familiar brands. Most say they depended upon personal sources when choosing a brand of frozen vegetables, but almost 25 percent read labels and consulted consumer publications. Topping the list of very important criteria for food selection among older persons is taste and enjoyment, but 45 percent say that nutritional value is very important also (64).

Guthrie, Black, and Madden showed that caloric intake decreases with age (66). Schlenker found "snacking or eating between meals is popular among older people and frequently occurs in the evening." (65) snacking is related to leisure time activity for many retired people. It is possible, 
therefore, that the more time spent watching television, the greater the percentage of total calories will be contributed by snacks. Evening television viewing has been positively correlated to both fat and calorie intakes among 47 New York elderly. The overall quality of the diet deteriorated as the proportion of calories from snacks increased. "On the average $14 \%$ of all calories (range $=6 \%$ to $52 \%$ ) came from snack foods" such as sweet baked items, crackers, fruit drinks, soft drinks, potato chips, and candy (65). Television is a favorite pastime for many older people, and Schlenker found that most elderly persons watched television about 5 hours daily (65).

Schlenker also found that the elderly generally rely on less formal sources of nutrition information, including: television, physicians, magazines, cookbooks, and newspapers. Television and newspapers most often provide information relating to new food products (65).

Mass media is a largely untapped resource for disseminating nutrition information. According to Schlenker, one effective way to utilize television may be through short sequences (I minute or less) such as public service announcements. Such messages require "no viewer interest or motivation, reaching its objective through repetition over days and weeks" (65). 


\section{SUMMARY}

Research shows that people are influenced by television advertisements, even if they are not engaged in active viewing. Advertising is big business, and companies spend a lot of money to promote their products. Government regulation of health claims has been recently relaxed. The use of health claims in food advertising is controversial. Audiences who may be influenced to the greatest degree by television food advertisements are the obese, the elderly, teenagers and children. 


\section{METHODS AND PROCEDURES}

\section{INTRODUCTION}

This study estimated the proportion of food and nutrition advertisements on television, and assessed the implied messages and presence of health claims in these advertisements, using content analysis techniques. Content analysis was used because its general-purpose infrastructure can be elaborated for a wide range of applications. Content analysis is a systematic method for obtaining data from and reaching conclusions about those communications ( 8 ). The component techniques of content analysis are unitization and classification. In unitization, one defines the units which are to be counted or measured. During classification, one sorts and categorizes the data. For this study, the units of interest were food and nutrition advertisements presented on television. The classifications consist of: (a) food and nutrition advertisements and (b) other advertisements. The food and nutrition advertisements were further categorized for: (a) implied health, science, fitness, and weight-control messages and (b) health claims.

\section{SAMPLING PLAN}

A representative sample of broadcast time was collected which took into account the following factors, or strata: 
- Type of station (network or independent)

- Day of week

- Time of day

- Duration of sampling

Twelve stations were selected from those available through the local cable company in Boca Raton, Florida. Six were network stations and six were independent. of the six available network stations, each of the "Big Three" was represented twice. The six independent stations were randomly selected from those available. Premium stations were not considered since they would have no advertisements. Two-hour samples were taken on all days of the week. Each day was divided into three 8-hour periods. Period 1 ran from 12:00 am to 7:59 am; Period 2, 8:00 am to 3:59 pm; and Period 3, 4:00 pm to 11:59 pm. Each 8-hour period contained four potential 2-hour samples.

Samples were two hours long since interviews with ad sales personnel at two local stations revealed that most stations program 16 minutes of advertisements for each hour $(2,7)$. For each two-hour sample, there would be about 32 minutes of advertisement time. Johnny-on the-Spot indicated about $18 \%$ of advertisements are devoted to food (17). Thus, in a typical two-hour sample, one would see about 6 minutes of food advertisements. Since most advertisements run 15-30 seconds, on average there would be 12-24 food advertisements in each two-hour sample. One or more of these advertisements would have implied messages or health claims. 
If the 2-hour sample were shorter, there would be less chance of acquiring enough food advertisements with a nutrition message. A longer sample was thought not to be justifiable in study time and cost. The broadcast material was taped continuously throughout the 2-hour sample.

The 2-hour samples were gathered over 28 consecutive days beginning May 8,1987 . The 28 day period allowed each week day to be sampled four times. Collecting data over a month helped control for any temporary bias in advertising content, such as that due to holidays.

Given 28 days and 12 stations, there were approximately 4000 potential samples. That number reduced to about 3300 if Period 1 is ignored for the network stations, since they are usually off the air at that time.

The following formula was used to determine the sample size (68). This formula was appropriate since the primary measures of interest in this study were proportions.

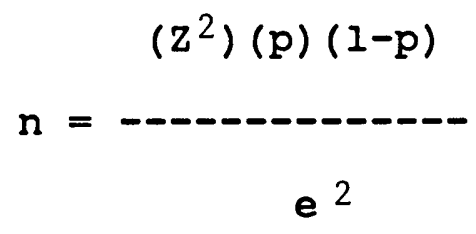

where

$\underline{z}=\mathrm{z}$-score for the level of confidence

$p=$ an estimate of the proportion

$\underline{e}=$ the maximum allowed error

$\underline{\mathrm{n}}=$ the sample size 
The following values were recommended by Walpole (68). The sample size ( $\underline{n})$ will be affected by the values of $\underline{z}, \underline{q}$, and $\underline{e}$. The value of $\underline{z}$ will determine the statistical confidence of the results. This confidence is the likelihood that if the study was conducted a second time one would obtain the same results. For larger $\underline{Z} s$ the confidence will be greater, and the sample size required to achieve this confidence will be larger. The value of 1.645 (908 confidence) was used as a reasonable confidence level for a manageable sample size.

$\mathrm{p}$ estimates the proportion one expects to obtain in a study. If this proportion is completely unknown then the most conservative estimate is .5 (68). In this study, the expected proportions of implied messages and health claims were unknown, so .5 was used for $\mathrm{p}$.

The allowable margin of error is represented by $\underline{e}$. The larger the value of $\underline{e}$, the greater is the allowed margin of error and the smaller will be the sample size necessary for this degree of accuracy. Initially, an e of .01 was considered, but substituting this value into the equation with the values above for $\underline{z}$ and $p$ led to an unmanageable sample size of 6766. Changing e to .l gives a reasonable margin of error while keeping the sample size under 100 . In fact, using $\underline{z}=1.645, \underline{p}=.5$, and $\underline{e}=.1$ led to an estimated sample size of 67 .

Thus, the minimum sample size for this study was determined to be 672 -hour samples. In order to obtain 
balanced coverage for the strata, 72 samples (the number closest to 67 which was divisible by 12) were collected. For the exact sampling plan used, see Appendix A. To summarize, 6 samples were taken from each of 12 stations. Network and independent stations were evenly represented with 36 samples each. Since network stations are usually off the air during Period 1, the 36 network samples were evenly divided among Periods 2-3, with 18 samples per period. Since the independent stations are usually on the air all day, the 36 independent samples were evenly divided among Periods 1-3, with 12 samples per period. To spread the samples along the 28 day duration of collection, two samples were taken each day on 12 days, and three samples were taken each day on 16 days, for a total of 72 samples. A day was assigned two or three samples by random assignment by drawing lots. The numbers 1 through 28 were written on slips of paper. The slips were placed into a container and shaken for 60 seconds. Twelve slips were removed, and two samples were selected from these days. Three samples were taken from each of the remaining 16 days.

Daily samples were selected using these steps:

1. A network station was selected using a random number table (69). The numbers 1 through 6 represented the stations in the following way:
1. WTVJ -4 (CBS)
4. WSVN-7 (NBC)
2. WTVX-34 (CBS)
5. WPLG-10 (ABC)
3. WPTV -5 (NBC)
6. WPEC-12 (ABC) 
starting from a randomly selected point in the table, the numbers were scanned. If a number was 0 or greater than 6 , it was ignored. The first number found between 1 and 6 indicated the selected station.

2. Either Period 2 or 3 was selected using even numbers to represent Period 2 and odd numbers to represent Period 3. Period 1 was eliminated from the sampling since it was expected to be static for the networks.

3. The numbers 1 to 4 were used to represent the specific 2-hour time slots in the selected period.

4. The procedure described in steps 1 through 3 above was repeated to select a sample from the independent stations. Period 1 was not eliminated for the independent stations since many of them are on the air for 24 hours per day. Stations were assigned to the numbers 1 through 6 in the following way:
1. WFLX -29
4. WDZL-39
2. WOR-9
5. $A \& E$
3. WTBS -17
6. USA

5. For three-sample days, the third sample was determined to be network or independent by the toss of a coin, with "heads" for network stations and "tails" for independent stations. After the type of station had been selected, the specific sample was determined using the procedure described in steps 1 through 3 or step 4 above, as applicable. 
6. A checklist was set up so the number of samples from each strata could be recorded. After a strata had been assigned the proper number of samples, no more assignments were made to that strata.

7. In addition to the sampling constraints imposed by the strata, sampling periods were not allowed to be consecutive in order to allow time for the researcher to change tapes and reset the recorder.

Program time was recorded using a Sony video Cassette Recorder, Model SL-5800. Each day for 28 days, the recorder was set to record program times according to the schedule in Appendix A.

\section{CONTENT ANALYSIS}

After data collection, the content of the program time was analyzed. Using a form designed for this study (Appendix B), the researcher analyzed the 72 hours of recorded material. Advertisements were identified and categorized as food and nutrition advertisements or non-food advertisements. Food and nutrition advertisements were categorized into 17 food classes:
1. Snacks
7. Condiments
13. Weight-Loss
2. Beverages
8. Supplements
14. Breads
3. Convenience
9. Meat
15. Restaurants
4. Cereal
10. Cookies
16. Supermarkets
5. Alcohol
11. Fats-oils
17. Baby-Food
6. Fast-Food
12. Cheese 
Each food and nutrition advertisement was classified as containing or not containing health claims. A health claim consisted of a nutritional fact and its consequence, such as, "No cholesterol, which means a reduced risk of heart attack".

Next, the researcher wrote down a list of descriptor words for the most prominent implied messages projected by the advertisement. After all of the advertisements had been rated in this way, all of the descriptor words (Appendix C) were organized into 22 categories, or scales (next page). The food and nutrition advertisements were re-examined to determine which of the 22 scales listed below were present as implied messages based on the descriptor words which had been listed for the advertisement.

1. The senses

2. Hearty/Satisfying

3. Healthy

4. Scientific

5. Fitness

6. Weight Control/Beauty

7. Macho

8. Sex

9. Youth

10. Adult

11. Fun
12. Peer Pressure

13. Friendship

14. Family Values

15. Trendy

16. Traditional

17. Convenience

18. Value

19. Special/Luxury

20. Variety/Choice

21. Extraordinary Claim

22. Product Comparisons

Finally, data were analyzed by the CRunch Interactive Statistical Program (CRISP), a statistical analysis program for the IBM Personal Computer (70). 
VERIFICATION OF THE RESEARCHER'S PERCEPTUAL RELIABILITY

To estimate the proportion of food and nutrition advertisements, and the proportion of implied messages and health claims in these advertisements, the researcher reviewed 72 hours of videotapes.

To measure the reliability of the researcher's perceptions of the nutritional claims and implied messages in the commercials, the nutritional claims and implied messages of 25 frequently presented advertisements were evaluated by both the researcher and a panel of ten local dietitians using a Health claims Questionnaire and a set of Likert scales based on 22 scales. (See Appendix D for forms.) Twenty-five advertisements were selected assuming the evaluation would take one to two minutes per commercial. As a consideration to panel members, total time required to complete the evaluation was under an hour.

All advertisements had already been placed into one of 17 categories according to type of product (e.g., cereal, snack, alcohol). The advertisements were collected into a list based on food class. The number of times each advertisement was recorded was placed next to the description of the advertisement. At least one commercial (the most frequent) was chosen from each of the 17 categories. The eight categories with the most advertisements had two commercials chosen (the two most frequent) so 25 advertisements were selected. These commercials were recorded on a videotape. A booklet containing participant 
instructions and forms for each advertisement (Appendix D) was developed for the researcher and each panel member. These 25 advertisements were recorded onto a videotape. The video-tape was viewed by the researcher and panel members. Following each commercial the tape was stopped and the forms (Likert scales and Health Claims Questionnaire) were completed. These data were analyzed for the inter-rater reliability. 


\section{RESULTS AND DISCUSSION}

THE PROPORTION OF FOOD AND NUTRITION ADVERTISEMENTS Proportion Calculated from this sample

of the 3547 advertisements in the sample, 725 were categorized as food and nutrition advertisements. This is a proportion of .20 . A 958 confidence interval for the proportion shows the accuracy of this estimate to be plus or minus .01, which gives a lower bound of .19 and an upper bound of .21.

Proportion Calculated from Johnny-on-the-Spot

The proportion of food and nutrition advertisements can also be calculated from the information provided in Johnnyon-the-spot (17). The sample in the January 1987 issue was based on extensive monitoring of one independent and three local network stations (WFLX, WPEC, WPTV, and WTVX) for a one week period. There were 6504 advertisements in that sample with 1121 food and nutrition advertisements, for a proportion of .18. A $95 \%$ confidence interval for this proportion also indicates that the accuracy is plus or minus .01, which gives a lower bound of .17 and an upper bound of .19.

The observed proportions from these independent samples are very close, suggesting that about 1 in 5 advertisements are food-related. Since the confidence intervals overlap 
(i.e., both contain the value .19), there is no statistical evidence that the values are different (69). These findings imply that the sampling procedure in this study was reliable.

\section{INTER-RATER RELIABILITY}

Inter-rater reliability was determined on a portion of the advertisements to measure the researcher's consistency with other dietitians' expert opinions. Ten dietitians observed the 25 video-taped advertisements and completed Likert scale forms for the implied messages and nutrition claims forms for the presence and accuracy of nutritional claims. After establishing the researcher's reliability, the content analysis of the 725 sampled food and nutrition advertisements was completed.

\section{Likert scale Correlations}

Overall Correlation: The averaged data from the Likert scales for both researcher and panel are shown in Table 1 . The correlation between these sets of numbers was highly significant $(\underline{r}=.70, d f=21, p=.0002)$. This suggests that, over the 25 advertisements, the researcher and the panel of dietitians were in good agreement in their recognition of the implied messages in the advertisements. 
Table 1. Likert scales averaged over the 25 advertisements for both the researcher and the panel

\begin{tabular}{|c|c|c|}
\hline Scale & Researcher & Panel \\
\hline The Senses & 3.88 & 4.74 \\
\hline Hearty/satisfying & 2.84 & 3.79 \\
\hline Healthy & 3.76 & 3.43 \\
\hline Scientific & 2.04 & 2.31 \\
\hline Fitness & 1.40 & 2.23 \\
\hline Beauty/Weight Control & 2.00 & 2.40 \\
\hline Macho & 1.40 & 2.27 \\
\hline Sex & 2.00 & 2.17 \\
\hline Youth & 2.80 & 3.13 \\
\hline Adult & 1.60 & 4.07 \\
\hline Fun & 3.92 & 3.86 \\
\hline Peer Pressure & 1.60 & 2.66 \\
\hline Friendship & 1.64 & 2.73 \\
\hline Family values & 1.52 & 2.45 \\
\hline Trendy & 2.64 & 3.41 \\
\hline Traditional & 1.28 & 2.69 \\
\hline Convenience & 2.00 & 3.51 \\
\hline Value & 2.24 & 2.88 \\
\hline Special/Luxury & 2.28 & 3.09 \\
\hline Variety/Choice & 2.32 & 2.69 \\
\hline Extraordinary Claim & 1.00 & 2.49 \\
\hline Product Comparisons & 1.92 & 2.49 \\
\hline
\end{tabular}


Correlations for Each Scale: Even though the researcher and panel were in good agreement overall, agreement was better for some scales than others. Table 2 shows the correlations and associated probabilities between the researcher and panel for each scale. Each correlation analysis was based on 24 degrees of freedom.

Agreement for Healthy, Scientific, and Beauty/ Weight Control scales was excellent, with $\underline{r}$-values exceeding .90 . (The Beauty/Weight Control scale will be referred to as the Weight control scale.) The correlation for the Fitness scale was also good $(\underline{r}=.75, d f=24, p=00002)$. The other scales were significantly correlated with the exception of the Peer Pressure and Traditional scales.

The following analyses will focus on the Healthy, Scientific, Fitness, and Weight control scales, since they are the scales of greatest importance to a dietitian and were significantly correlated. Figures 1 through 4 illustrate correlations between the researcher and panel on these scales.

The good agreement between the researcher's and panel's perceptions, especially agreement found for the Healthy, Scientific, Fitness and Weight Control scales, make it reasonable to conclude that the researcher's perceptions of these messages are reliable. Therefore, the researcher's evaluations on these four scales were legitimately examined in the analysis of the 725 food and nutrition advertisements. 
Table 2. Correlations between the researcher's and panel's responses for each likert scale

\begin{tabular}{|c|c|c|}
\hline Scale & Correlation (r) & Probability \\
\hline The Senses & .80 & .000002 \\
\hline Hearty/satisfying & .75 & .00002 \\
\hline Healthy & .91 & .0000000 \\
\hline Scientific & .92 & .0000000 \\
\hline Fitness & .75 & .00002 \\
\hline Beauty/Weight Control & .94 & .0000000 \\
\hline Macho & .83 & .0000004 \\
\hline Sex & .84 & .0000003 \\
\hline Youth & .85 & .0000002 \\
\hline Adult & .43 & .03 \\
\hline Fun & .83 & .0000004 \\
\hline Peer Pressure & -.24 & .25 \\
\hline Friendship & .68 & .0002 \\
\hline Family Values & .77 & .000007 \\
\hline Trendy & .60 & .0015 \\
\hline Traditional & .17 & .42 \\
\hline Convenience & .79 & .00003 \\
\hline Value & .85 & .0000002 \\
\hline Special/Luxury & .52 & .008 \\
\hline Variety/Choice & .87 & .0000002 \\
\hline Extraordinary Claim & $---*$ & \\
\hline Product Comparisons & .83 & .0000004 \\
\hline
\end{tabular}

* Cannot be calculated since the researcher's ratings had no variability. 
1 Kellogg's Rice Krispies

2 Columbian Coffee

3 Stouffer's Lean Cuisine

4 Honey Nut Cheerios

5 Wonder Bread

6 Promise Margarine

7 Jello Fruit/Cream Bars

8 Jello No-Bake Pies

9 Coca-Cola

10 Dr.'s Quick Weight Loss

11 Young/Tender Brand Chicken

12 Seagram's Coolers

13 Weight Watcher's Entrees

14 Wendy's

15 Slim Fast

16 Beechnut Baby Food

17 Miller Lite

18 7-11 Stores

19 Heinz Ketchup

20 Drumstick Ice Cream Cones

21 Keebler EL Fudge

22 McDonald's Salads

$23 \mathrm{JL}$ Kraft Dressing

24 Nabisco Shredded Wheat

25 Int. House of Pancakes

$$
(r=.91, d f=24, p=.0)
$$
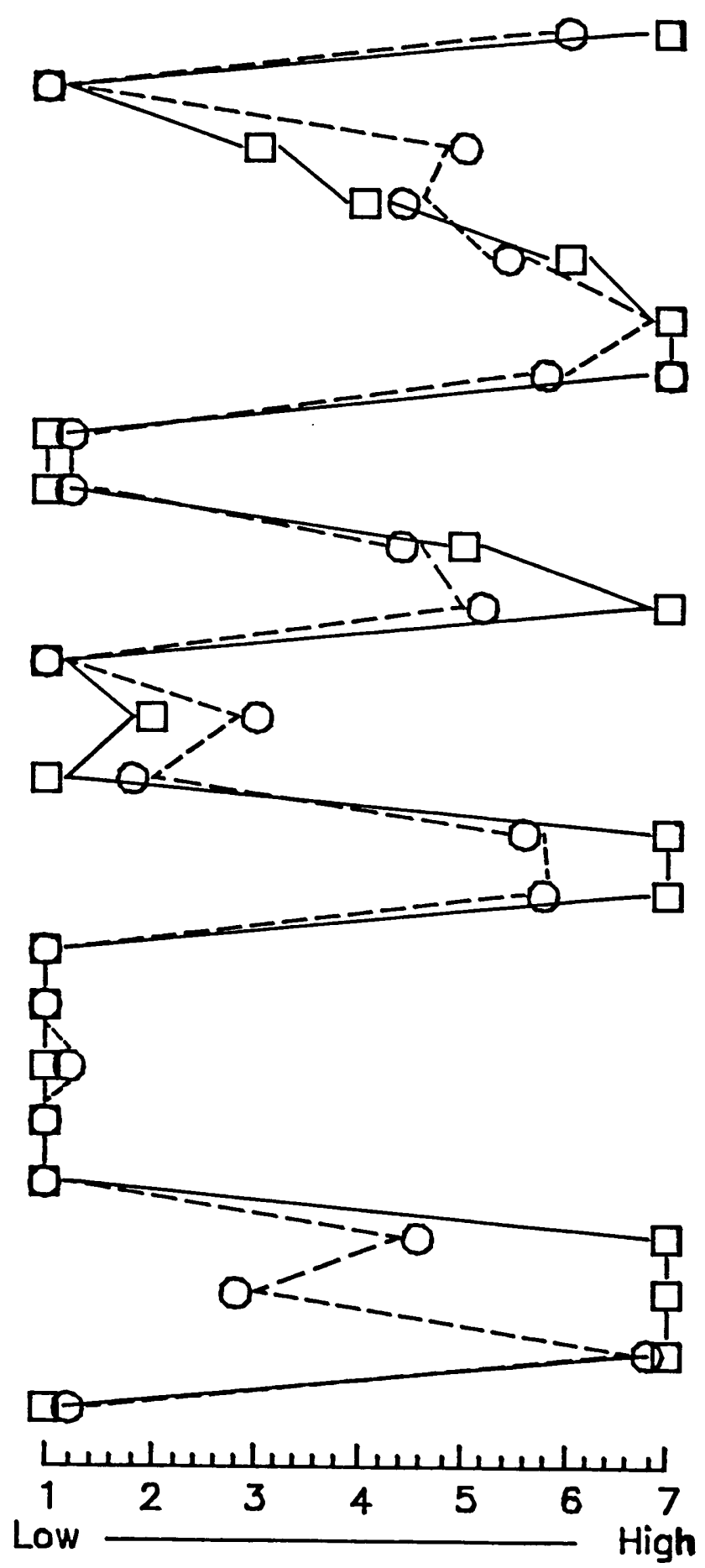

Degree of Emphasis

FIG. 1. Correlation between the researcher's and panel's Likert scale responses for the Healthy scale. The data for the panel is the mean response of the 10 panel members. 
1 Kellogg's Rice Krispies

2 Columbian Coffee

3 Stouffer's Lean Cuisine

4 Honey Nut Cheerios

5 Wonder Bread

6 Promise Margarine

7 Jello Fruit/Cream Bars

8 Jello No-Bake Pies

9 Coca-Cola

10 Dr.'s Quick Weight Loss

11 Young/Tender Brand Chicken

12 Seagram's Coolers

13 Weight Watcher's Entrees

14 Wendy's

15 Slim Fast

16 Beechnut Baby Food

17 Miller Lite

18 7-11 Stores

19 Heinz Ketchup

20 Drumstick Ice Cream Cones

21 Keebler EL Fudge

22 McDonald's Salads

$23 \mathrm{JL}$ Kraft Dressing

24 Nabisco Shredded Wheat

25 Int. House of Pancakes

$$
(r=.92, d f=24, p=.0)
$$
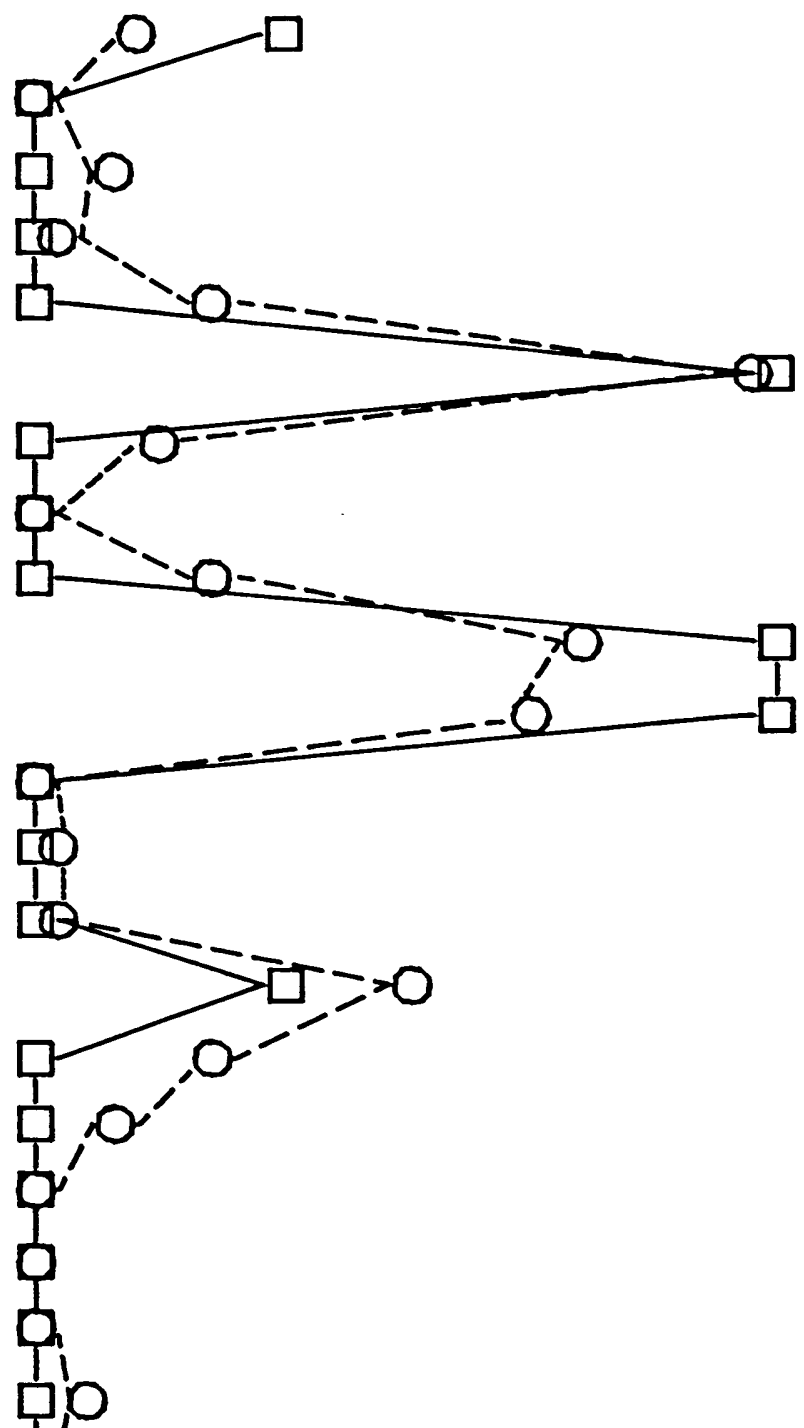

$\frac{1}{6}$

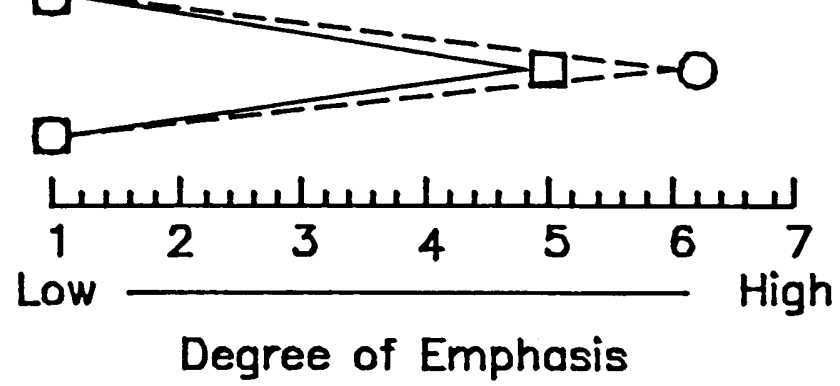

FG. 2, Correlation between the researcher's and panel's Likert scale responses for the Scientific scale. The data for the panel is the mean response of the 10 panel members. 
1 Kellogg's Rice Krispies

2 Columbian Coffee

3 Stouffer's Lean Cuisine

4 Honey Nut Cheerios

5 Wonder Bread

6 Promise Margarine

7 Jello Fruit/Cream Bars

8 Jello No-Bake Pies

9 Coca-Cola

10 Dr.'s Quick Weight Loss

11 Young/Tender Brand Chicken

12 Seagram's Coolers

13 Weight Watcher's Entrees

14 Wendy's

15 Slim Fast

16 Beechnut Baby Food

17 Miller Lite

18 7-11 Stores

19 Heinz Ketchup

20 Drumstick Ice Cream Cones

21 Keebler EL Fudge

22 McDonald's Salads

$23 \mathrm{JL}$ Kraft Dressing

24 Nabisco Shredded Wheat

25 int. House of Pancakes

$$
(r=.75, d f=24, p=.00002)
$$

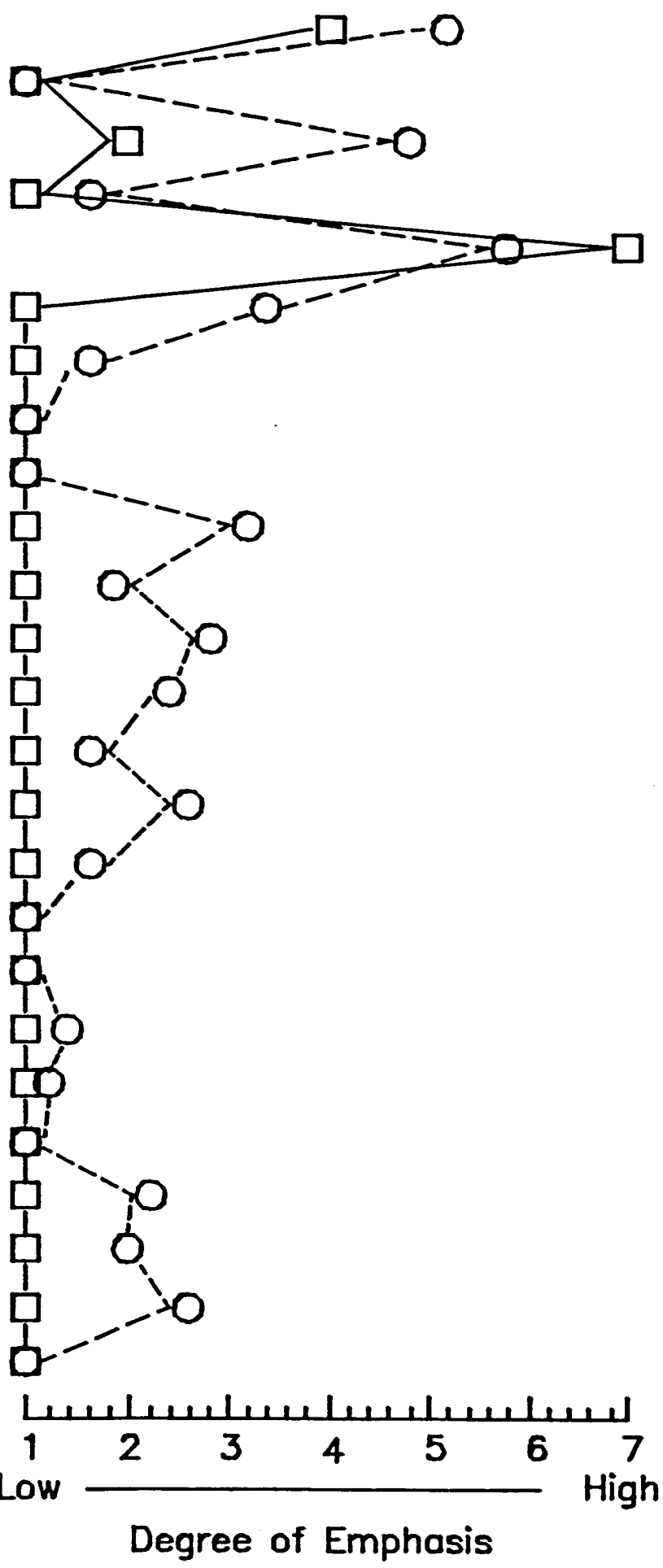

FG. 3. Correlation between the researcher's and panel's Likert scale responses for the Fitness scale. The dato for the panel is the mean response of the 10 panel members. 


\section{Advertisement}

1 Kellogg's Rice Krispies

2 Columbian Coffee

3 Stouffer's Lean Cuisine

4 Honey Nut Cheerios

5 Wonder Bread

6 Promise Margarine

7 Jello Fruit/Cream Bars

8 Jello No-Boke Pies

9 Coca-Cola

10 Dr.'s Quick Weight Loss

11 Young/Tender Brand Chicken

12 Seogram's Coolers

13 Weight Watcher's Entrees

14 Wendy's

15 Slim Fost

16 Beechnut Baby Food

17 Miller Lite

187-11 Stores

19 Heinz Ketchup

20 Drumstick Ice Cream Cones

21 Keebler EL Fudge

22 McDonald's Salads

23 Jll Kraft Dressing

24 Nabisco Shredded Wheat

25 Int. House of Pancakes

$$
(r=.94, d f=24, p=.0)
$$

Researcher: $\square$

Panel: 0
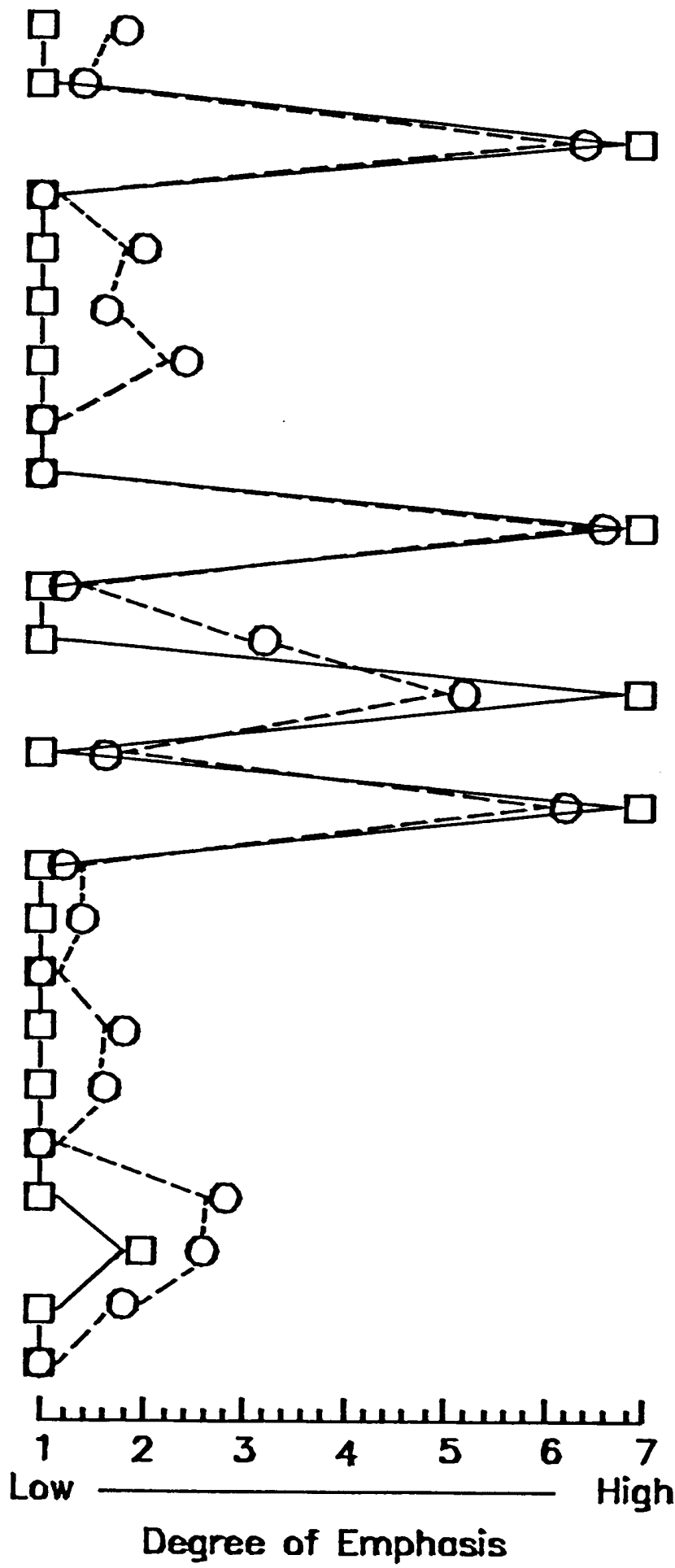

FG. 4. Correlation between the researcher's and panel's Likert scale responses for the Weight Control scale. The data for the panel is the mean response of the 10 panel members. 
Reliability for Presence and Accuracy of Health Claims

Reliability analysis was conducted using a statistic, kappa ()ㅡ, which is most often applied to inter-rater reliability problems where the data has been counted rather than measured on a scale (71). Kappa is similar to the correlation coefficient $(\underline{r})$ in that it may have values between +1 and -1 , where +1 indicates complete agreement, -1 indicates complete disagreement, and 0 indicates that the ratings are independent or unrelated. In general, kappas above .75 indicate excellent agreement, those below .40 indicate poor agreement, and those between .40 and .75 indicate fair to good agreement (71).

Presence of Health claims: Table 3 shows the way in which the researcher (Res) and panel (P1-P10) detected health claims in the 25 advertisements. A "Y" meant that the observer reported a health claim in the advertisement, while a blank means no health claim was detected. The overall kappa was calculated using the responses of the researcher and the ten panel members, and was found to indicate good agreement $(\underline{k}=.61, \underline{p}=.000001)$. In order to compare the researcher with the panel, the panel's responses were counted to determine the majority opinion for each advertisement. This is shown in Table 3 under the column labeled "Majority". The majority opinion for Advertisement 16 was evenly divided. In such cases, Bradley has suggested calculating the statistic twice; once with one value of the tied observation and once with the other (69). If both calculations lead to 
Table 3. Detection of health claims by researcher and panel members

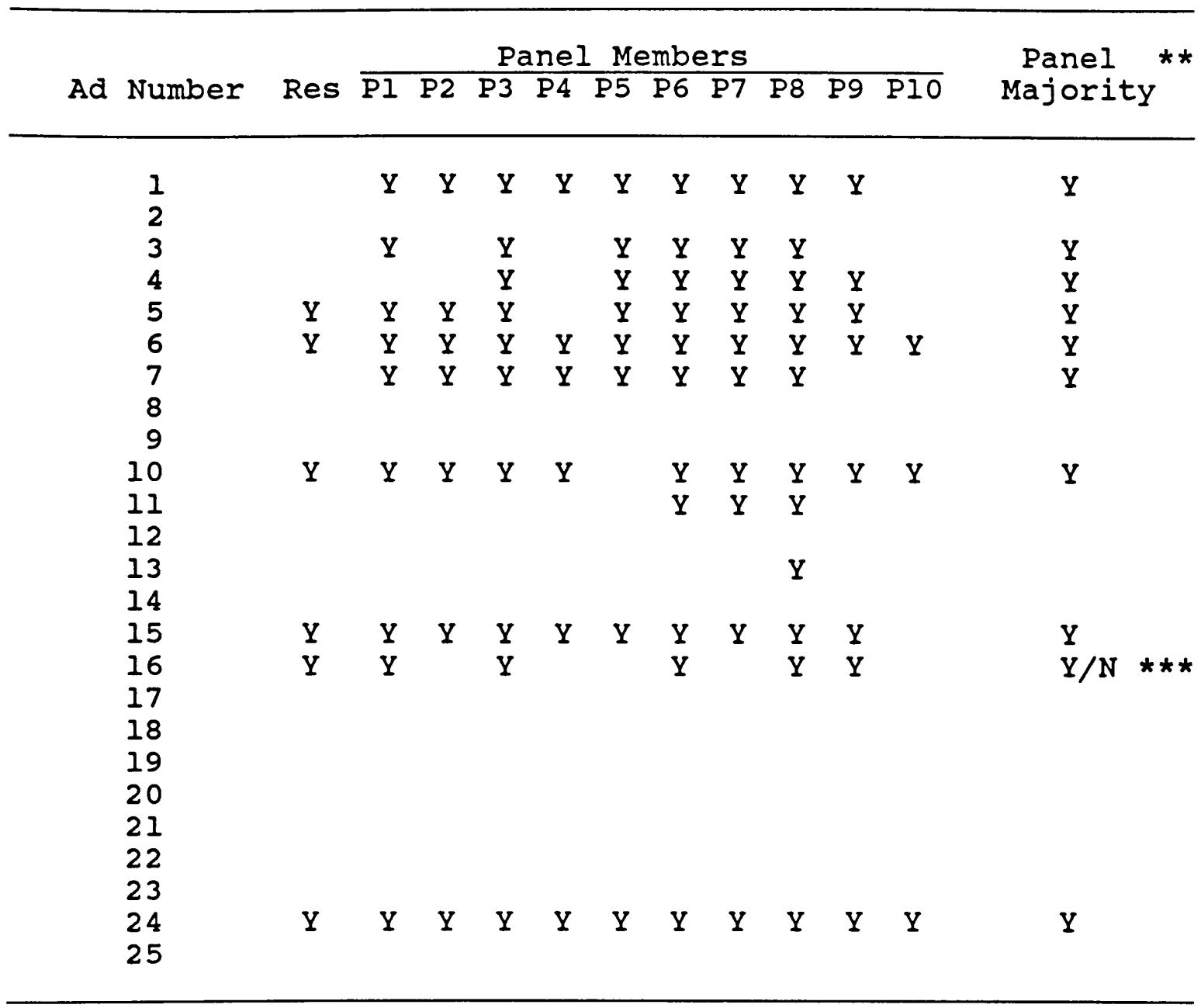

* A blank indicates that the subject did not believe a health claim had been made in the advertisement. A "Y" indicates that the subject did believe a health claim was made.

** Majority opinion is that expressed by the greatest number of panel members.

*** The majority opinion was evenly divided. 
the same conclusion, then there is no problem. If the calculations lead to different conclusions, then one must declare the results to be uninterpretable. Following this recommendation, kappa was calculated twice. The first time, Advertisement 16 was counted as a "Y" ( $\underline{k}=.64, \underline{p}=.0002)$, and the second time it was counted as an "N" ( $\underline{k}=.55, \underline{p}=.0002)$. Either value of kappa leads to the same conclusion, that the agreement between the researcher and the panel is good. Accuracy of Health claims: Table 4 shows the way in which the researcher (Res) and panel (P1-P10) assessed the accuracy of the health claims in the ten advertisements which were determined to have health claims by the majority opinion of the observers. Only these ten advertisements were included for the reliability analysis of the accuracy of health claims since the other fifteen had no claims to assess. In Table 4, an "A" meant the claim was rated as accurate, an "I" indicated a rating of inaccurate, and an "X" signified that the observer didn't detect a health claim. The overall inter-rater reliability was very poor $(\underline{k}=.07$, $\mathrm{p}=.01$ ). As before, a majority column was created by determining whether the panel had given an advertisement more "A"s, "I"s, or "X"s so the researcher's ratings could be compared against the majority opinion of the panel. The majority opinion was evenly divided in two cases: Advertisement 3 and Advertisement 7. The tie in Advertisement 7 was unimportant since neither of the possible 
Table 4. Researcher and panel member assessment of health claim accuracy

Panel Members

Panel **

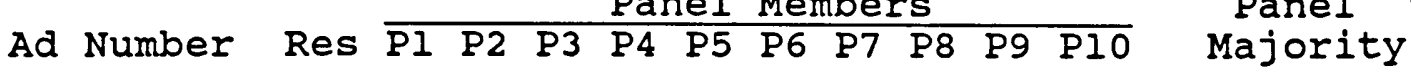

\begin{tabular}{|c|c|c|c|c|c|c|c|c|c|c|c|c|c|}
\hline 1 & $x$ & $I$ & $I$ & A & A & $I$ & $I$ & $I$ & A & A & $x$ & I & \\
\hline 3 & $X$ & A & $x$ & $\mathrm{~A}$ & $X$ & $I$ & $I$ & A & A & $x$ & $x$ & $A / X$ & $\star \star \star *$ \\
\hline 4 & $x$ & $x$ & $X$ & I & $x$ & A & $I$ & $I$ & A & A & $x$ & $\mathrm{X}$ & \\
\hline 5 & $I$ & $I$ & $I$ & $I$ & $x$ & $I$ & $I$ & $I$ & $I$ & $I$ & $x$ & I & \\
\hline 6 & $\mathrm{~A}$ & $I$ & A & A & A & A & $I$ & A & A & A & $I$ & $A$ & \\
\hline 7 & $x$ & $I$ & $I$ & $I$ & A & A & A & A & I & $X$ & $x$ & $A / I$ & $* * *$ \\
\hline 10 & $I$ & $I$ & $I$ & $I$ & A & $x$ & $I$ & A & I & A & I & $I$ & \\
\hline 15 & $I$ & $I$ & $I$ & A & A & I & $I$ & $I$ & $I$ & A & $X$ & $I$ & \\
\hline 16 & $\mathrm{~A}$ & A & $X$ & A & $x$ & $x$ & $I$ & $X$ & A & A & $x$ & $x$ & \\
\hline 24 & I & $I$ & A & A & A & $I$ & $I$ & I & A & A & A & $A$ & \\
\hline
\end{tabular}

An "A" indicates that the health claim was believed to be accurate. An "I" indicates that the health claim was believed to be inaccurate. An " $X$ " indicates that the subject did not believe a health claim had been made, and therefore did not assess accuracy.

** Majority opinion is that expressed by the greatest number of panel members.

*** The majority opinion was evenly divided. 
majority opinions matched that of the researcher, and the value of kappa is solely determined by the proportion of matches (71). The tie in Advertisement 3 was important, however, since in one case the majority opinion matched that of the researcher. Again following Bradley's recommendation, kappa was calculated twice (69). The first time, Advertisement 3 was counted as an "A" ( $\underline{k}=.26, \underline{p}=.03)$, and the second time it was counted as an "X" $(\underline{k}=.39, \underline{p}=.03)$. Either value of kappa leads to the same conclusion, that the agreement between the researcher and the panel was better than the overall kappa, but still poor.

This indicated that there was reliability regarding the presence of health claims in advertisements, but not in determining the accuracy of those claims. The implications for this study were that further analysis of the presence of health claims in the 725 advertisements rated by the researcher was warranted, but conclusions about the accuracy of the health claims were not justified.

\section{Discussion}

The results of the analyses of inter-rater reliability showed that the ratings of the researcher were consistent with those of a panel of dietitians. Since the ratings are reliable, continued analysis of the 725 advertisements assessed by the researcher was justified. However, the dietitians were in poor agreement concerning the accuracy of 
the health claims. Therefore, an attempt to answer the research question concerning the accuracy of health claims was not justified. 
CONTENT ANALYSIS

Content analysis of the 725 food and nutrition advertisements was conducted to assess the effects of such independent variables as type of station (independent or network), period of day, day of week, and food class. The dependent variables included proportions of Healthy, Scientific, Fitness, and Weight control implied messages and proportion of health claims. Finally, important two-way interactions among the independent variables were analyzed.

Proportion of Health Claims

The proportion of food and nutrition advertisements containing health claims was found to be .11. A $95 \%$ confidence interval for this proportion had a lower bound of .09 and an upper bound of .135. About one in ten food advertisements contained a health claim.

Correlation Analysis of the Implied Messages Scales

The correlations among the Healthy, Scientific, Fitness, and Weight Control scales were calculated. If any of the scales were highly correlated $(\underline{r}>.75)$, then there would be little point in separately analyzing the highly correlated scales. When variables are highly correlated, they are likely to be measuring the same basic parameter, and analyses of the variables will yield similar results (69). Table 5 shows the correlations among the implied messages scales. 
Although the relationship among some of the scales differed significantly from $0(p<.05)$, none of the scales were highly correlated. The strongest correlation, between the Scientific and Weight Control scales, was only .22 . These results indicated that all four implied message scales should be separately analyzed.

Effect of Station Type (Independent vs. Network)

The effect of station type on the proportion of Healthy, Scientific, Fitness, and Weight Control implied messages and the proportion of health claims is shown in Table 6 . The effects have been assessed with z-tests (68). There were no significant difference between independent and network stations for the proportion of scientific messages or the proportion of health claims. The differences for the Healthy, Fitness, and Weight Control proportions were significant.

The network stations emphasize Healthy messages more than the independent stations. The independent stations emphasize more Fitness and Weight Control messages.

Rationale for Eliminating Period 1 Advertisements

Table 7 shows the number of food and nutrition advertisements occurring in each period of the day for both independent and network stations. 
Table 5. Correlations Among the Healthy, Scientific, Fitness, and Weight Control scales

\begin{tabular}{lcc}
\hline \multicolumn{1}{c}{ Scales } & Correlation $(r)$ & Probability $(p)$ \\
\hline Healthy-Scientific & -0.08 & .03 \\
Healthy-Fitness & 0.07 & .07 \\
Healthy-Weight Control & 0.00 & .93 \\
Scientific-Fitness & -0.01 & .78 \\
Scientific-Weight Control & 0.22 & .0001 \\
Fitness-Weight Control & -0.04 & .27 \\
\hline
\end{tabular}


Table 6. Differences between types of stations for proportions of food advertisements with Healthy, Scientific, Fitness, and Weight Control messages and health claims

Dependent

Variable

Healthy

scientific

Fitness

Weight Control

Health Claims
Station Type Independent Network Difference

Z

$\mathrm{p}$

\begin{tabular}{lllllll}
\hline Healthy & 0.328 & 0.408 & -0.080 & -2.13 & .03 & $*$ \\
Scientific & 0.008 & 0.013 & -0.005 & -0.61 & .54 \\
Fitness & 0.023 & 0.002 & 0.021 & 2.79 & .005 & * \\
Weight control & 0.225 & 0.104 & 0.121 & 4.41 & .00001 \\
Health claims & 0.099 & 0.119 & -0.020 & -0.82 & .40 \\
\hline
\end{tabular}

* Statistically significant, $p<.05$. 
Table 7. Number of food advertisements for each period of day and station type

\begin{tabular}{cccc}
\hline & \multicolumn{3}{c}{ Period of Day } \\
\cline { 2 - 4 } Station Type & Period 1 & Period 2 & Period 3 \\
Independent & 15 & 100 & 147 \\
Network & $*$ & 262 & 201 \\
\hline $\begin{array}{l}\text { No sampling was performed for this period and station } \\
\text { type. }\end{array}$
\end{tabular}


As discussed in Chapter 3, no samples were taken for Period 1 for the network stations since they are usually off the air at that time (12:00 midnight - 7:59 am). Samples were taken for the independent stations, but, as shown in Table 7, only 15 food and nutrition advertisements were telecast by the independent stations during Period 1. These 15 advertisements constitute only $2 \%$ of the entire sample, and are not likely to have any measurable effect on the results. Keeping them in the sample resulted in an unbalanced design, complicating further analysis. For these reasons, these 15 advertisements were not considered in any additional analyses.

Effect of Period of Day

The effect of the period of the day on the proportion of Healthy, Scientific, Fitness, and Weight Control implied messages and the proportion of health claims is shown in Table 8. The effects have been assessed with z-tests (68). Period 2 is the morning/afternoon period, from 8:00 am to 3:59 pm, and Period 3 is the evening period, from 4:00 pm to $11: 59 \mathrm{pm}$.

There were no significant differences $(\mathrm{p}<.05)$ for the Healthy, Fitness, or Weight Control messages. Period 2 had a greater proportion of scientific messages and health claims than Period 3. 
Table 8. Differences between periods of the day for proportions of food advertisements with Healthy, Scientific, Fitness, and Weight control messages and health claims

Dependent

Variable
Period of Day Period 2 Period 3 Difference $z \quad p$

Healthy

0.409

0.342

0.067

$1.84 \quad .07$

Scientific

0.019

0.003

0.016

2.03

.04

Fitness

0.008

0.011

$-0.003$

$-0.41 \quad .68$

Weight Control

0.146

0.155

$-0.009$

$-0.33 \quad .74$

Health claims

0.144

0.078

0.066

2.79 .005 *

* Statistically significant, $p<.05$. 
Effect of the Days of the Week

An interesting pattern was noted for the distribution of food advertisements over the days of the week. The number of food advertisements drops significantly $\left(\underline{x^{2}}=44, d f=6, p=.00001\right)$ on saturday. This pattern is illustrated in Figure 5.

The effect of the days of the week on the proportion of Healthy, Scientific, Fitness, and Weight Control implied messages and the proportion of health claims is shown in Table 9. The effects have been assessed with F-tests for a one-way analysis of variance (ANOVA) (72). All the tests were based on 6 and 718 degrees of freedom, and none were significant $(\mathrm{p}<.05)$.

Effects of Food Class

Table 10 shows the seventeen food classes defined in this study, the number code for each class, and the proportion of the sample accounted for by each class.

The top five classes accounted for $66 \%$ of the food and nutrition advertisements; the top ten, $90 \%$.

The effect of the days of the week on the proportion of Healthy, Scientific, Fitness, and Weight control implied messages and the proportion of health claims is shown in Table 11. The effects have been assessed with $F$-tests for a one-way ANOVA (72). All the tests were based on 16 and 708 degrees of freedom, and all were significant. 
Number of Food Ads

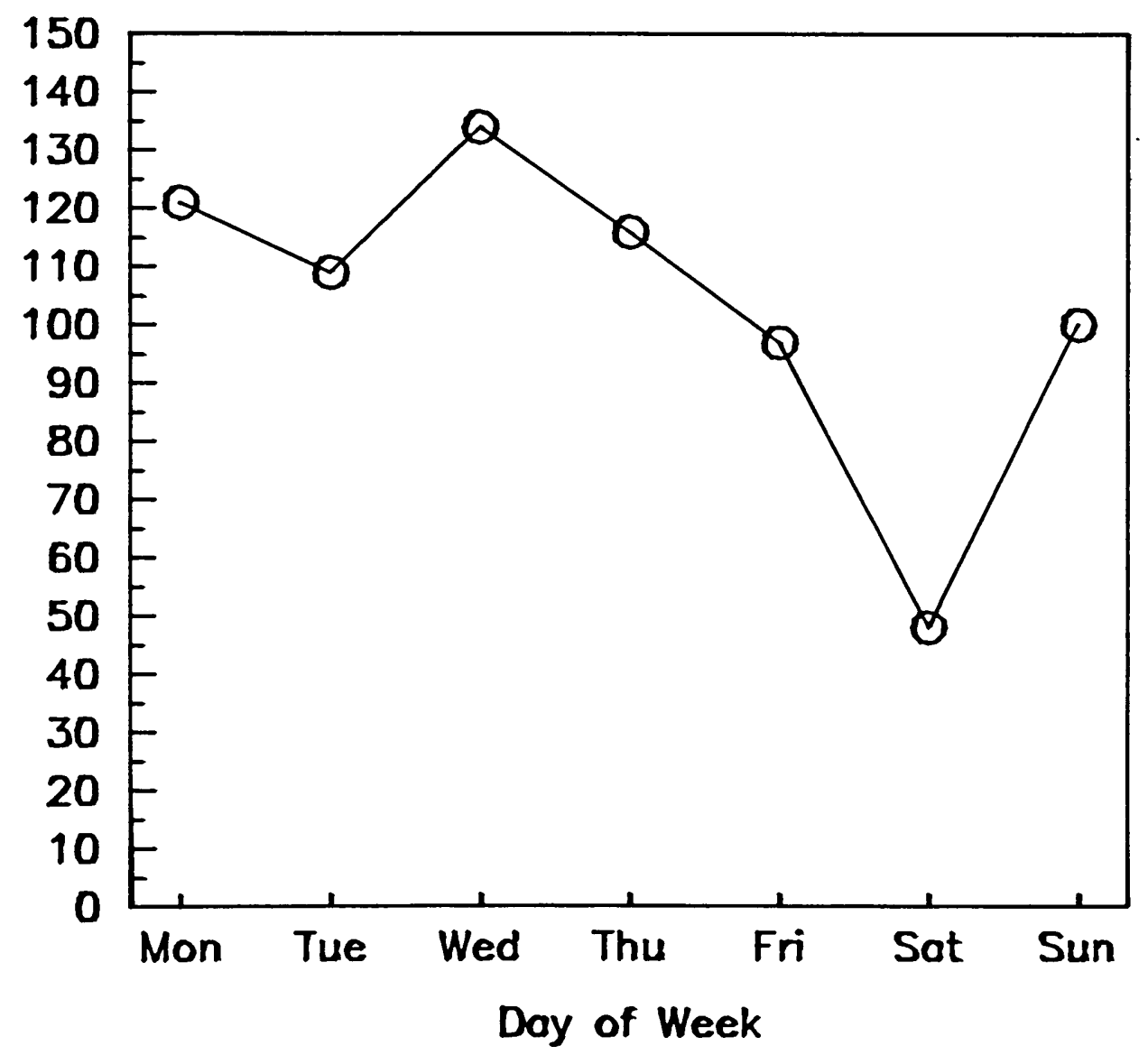

FG. 5. Distribution of food advertisements over the doys of the week. 
Table 9. Comparison of days of the week for the proportions of food advertisements with Healthy, Scientific, Fitness, and Weight control messages and health claims

\begin{tabular}{lccccccccc}
$\begin{array}{l}\text { Dependent } \\
\text { Variable }\end{array}$ & Mon Tue Wed Thu Fri Sat sun & $F$ & $\mathrm{p}$ \\
\hline Healthy & .42 & .38 & .41 & .41 & .35 & .31 & .31 & 0.889 & .51 \\
Scientific & .01 & .03 & .01 & .00 & .00 & .02 & .01 & 0.964 & .45 \\
Fitness & .02 & .00 & .02 & .01 & .00 & .00 & .01 & 0.891 & .50 \\
Weight Control & .17 & .15 & .13 & .12 & .16 & .13 & .17 & 0.328 & .93 \\
Health Claims & .12 & .11 & .13 & .08 & .16 & .02 & .12 & 1.709 & .11 \\
\hline
\end{tabular}


Table 10. Proportions of advertisements for seventeen food classes

Food Class

Proportion

Snacks

Beverages

Convenience

Cereal

Alcohol

Fast Food

Condiments

supplements

Meat

Cookies

Fats-oils

Cheese

Weight Loss

Breads

Restaurants

supermarkets

Baby Food
.190

.183

.109

.095

.086

.074

.058

.046

.039

.019

.017

.015

.015

.014

.014

.014

.012 
Table 11. Comparisons of 17 food classes for the proportion of advertisements with Healthy, Scientific, Fitness, and Weight control messages and health claims

\begin{tabular}{|c|c|c|c|}
\hline $\begin{array}{l}\text { Dependent } \\
\text { Variable }\end{array}$ & $\mathbf{F}$ & $p$ & \\
\hline Healthy & 10.11 & .0000 & * \\
\hline scientific & 55.25 & .0000 & * \\
\hline Fitness & 7.07 & .0000 & * \\
\hline Weight control & 11.12 & .0000 & * \\
\hline Health Claims & 34.64 & .0000 & * \\
\hline
\end{tabular}

* Statistically significant, $p<.05$, using a l-way analysis of variance. 
These results were further analyzed with Bonferroni $t-$ tests, a multiple comparisons test in which all proportions are compared with one another (72). Tables 12 to 16 show the results of these tests for the dependent variables in Table 11. Proportions which are connected by a column of asterisks are not significantly different from one another, but those which are not connected are significantly different $(p<.05)$. The food classes which most emphasized Healthy messages were fats-oils, cheese, baby food, cereals, supplements, meat, and breads.

Almost all scientific implied messages in food and nutrition advertisements were in weight loss advertisements. There were no other significant differences, and most of these proportions were 0.0 .

Almost all Fitness implied messages in food and nutrition advertisements were in bread advertisements. There were no significant differences among other food classes, and most of these proportions were 0 .

As expected, weight loss advertisements projected a Weight Control message; a higher proportion than any other food class. Supplements, bread, convenience foods, and cheese also had a relatively high proportion of weight Control messages.

The food classes most likely to make a health claim were fats-oils and weight loss. The other classes with a relatively high proportion of health claims were supplements, cheese, cereal, and baby food. 
Table 12. Proportions of advertisements with Healthy messages for each food class

Food Class

Proportion

Asterisk Columns *

Fats-oils

1.000

Cheese

0.909

Baby Food

0.889

Cereals

0.667

Supplements

0.595

Meat

0.536

Breads

0.500

Snacks

0.406

Beverages

0.364

Fast Food

0.333

Condiments

0.286

Convenience

0.215

cookies

0.143

Restaurants

0.100

Alcohol

0.065

Weight Loss

0.000

Supermarkets

0.000

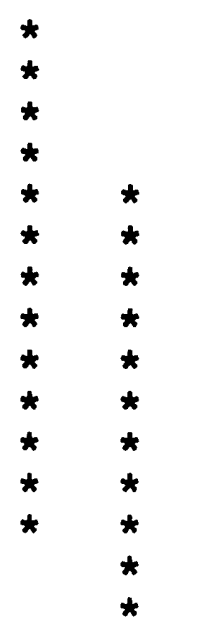

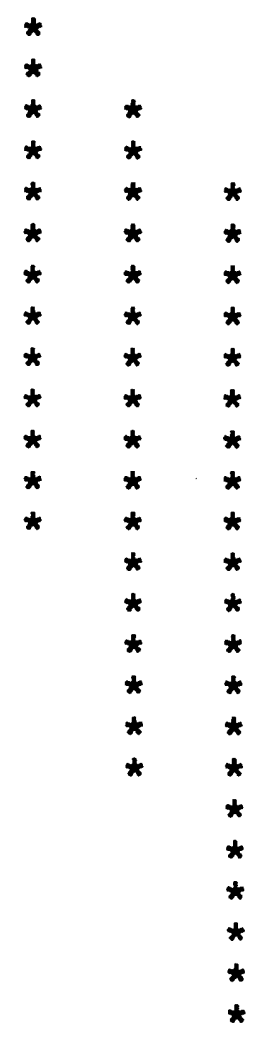

* Proportions joined by a column of asterisks were not significantly different $(p<.05)$ using Bonferroni t-tests. 
Table 13. Proportions of advertisements with Scientific messages for each food class

\begin{tabular}{|c|c|c|c|}
\hline Food Class & Proportion & Asterisk & Columns \\
\hline Weight Loss & 0.636 & * & \\
\hline supplements & 0.027 & $\begin{array}{l}\star \\
\star\end{array}$ & \\
\hline snacks & 0.011 & $\begin{array}{l}* \\
\star\end{array}$ & \\
\hline Beverages & 0.000 & $\begin{array}{l}\star \\
\star\end{array}$ & \\
\hline Convenience & 0.000 & * & \\
\hline Cereal & 0.000 & $\begin{array}{l}\star \\
\star\end{array}$ & \\
\hline Alcohol & 0.000 & * & \\
\hline Fast Food & 0.000 & $\begin{array}{l}\star \\
\star\end{array}$ & \\
\hline Condiments & 0.000 & $\begin{array}{l}* \\
\star\end{array}$ & \\
\hline Meat & 0.000 & $\begin{array}{l}\star \\
\star\end{array}$ & \\
\hline Cookies & 0.000 & $\begin{array}{l}\text { * } \\
\text { * }\end{array}$ & \\
\hline Fats-oils & 0.000 & $\begin{array}{l}* \\
\star\end{array}$ & \\
\hline Cheese & 0.000 & $\begin{array}{l}\star \\
\star\end{array}$ & \\
\hline Breads & 0.000 & $\begin{array}{l}* \\
\star\end{array}$ & \\
\hline Restaurants & 0.000 & $\begin{array}{l}\star \\
\star\end{array}$ & \\
\hline supermarkets & 0.000 & $\begin{array}{l}* \\
\star\end{array}$ & \\
\hline Baby Food & 0.000 & $\star$ & \\
\hline
\end{tabular}

* Proportions joined by a column of asterisks were not significantly different $(p<.05)$ using Bonferroni t-tests. 
Table 14. Proportions of advertisements with Fitness messages for each food class

Food Class

Breads

Alcohol

Cereal

snacks

Beverage

Convenience

Fast Food

Condiments

Supplements

Meat

Cookies

Fats-oils

Cheese

Weight Loss

Restaurants

Supermarkets

Baby Food
Proportion

Asterisk Columns

0.300 *

0.032

0.029

0.000

0.000

0.000

0.000

0.000

0.000

0.000

0.000

0.000

0.000

0.000

0.000

0.000

0.000

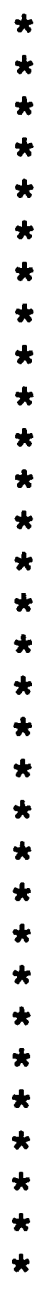

* Proportions joined by a column of asterisks were not significantly different $(p<.05)$ using Bonferroni t-tests. 
Table 15. Proportions of advertisements with Weight control messages for each food class

Food Class

Weight Loss

Supplements

Bread

Convenience

Cheese

Snacks

Beverages

Fats-oils

Fast Food

Meat

Cereal

Alcohol

condiments

cookies

Restaurants

supermarkets

Baby Food
Proportion

1.000

0.460

0.300

0.266

0.182

0.174

0.171

0.083

0.074

0.071

0.000

0.000

0.000

0.000

0.000

0.000

0.000
Asterisk Columns 
Table 16. Proportions of advertisements with health claims for each food class

Food Class

Fats-oils

Weight Loss

supplements

Cheese

Cereal

Baby Food

Convenience

Condiments

Beverages

snacks

Alcohol

Fast Food

Meat

cookies

Breads

Restaurants

Supermarkets
Proportion Asterisk Columns

0.333

0.063

0.024

0.008

0.000

0.000

0.000

0.000

0.000

0.000

0.000

0.000
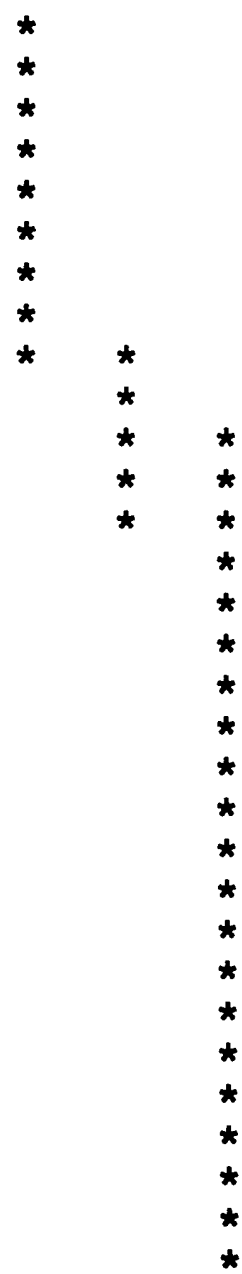

* Proportions joined by a column of asterisks were not significantly different $(p<.05)$ using Bonferroni t-tests. 
Analysis of Saturday Morning/Afternoon Cereal and Snack Advertisements

The sample contained 11 food and nutrition advertisements recorded on a saturday during Period 2 (morning/afternoon). Five of these advertisements were for snacks and four were for cereals. Therefore, the proportion of Saturday morning/afternoon food advertisements for cereals was .36 , and for snacks was .45 . The proportions for the rest of the sample were calculated based on the remaining 699 food and nutrition advertisements. There were 62 other cereal advertisements and 128 other snack advertisements, so the proportions were .09 for cereals and .18 for snacks. The proportion of cereal and snack advertisements is significantly greater on saturday morning/afternoon (Cereals, $\underline{z}=3.04, \underline{p}=.002 ;$ snacks, $\underline{z}=2.29, \underline{p}=.02)$.

Saturday morning cereal advertisements were compared to all other cereal advertisements for the presence of health claims. There were 66 cereal advertisements in the sample of 710 food advertisements. Of the four cereal advertisements (out of 11) shown on Saturday in Period 2, none made a health claim. Of the 62 other cereal advertisements in the sample (out of 699), the proportion making health claims was .44. A one-tailed $\underline{z}$-test of this difference was significant $(\underline{z}=1.73$, $\mathrm{p}=.04$ ). It appears that health claims are not a part of saturday morning cereal advertisements. 
Station Type by Period of Day: The interaction between the station type and the period of the day for the proportion of Healthy, Scientific, Fitness, and Weight Control implied messages and the proportion of health claims is shown in Table 17. Interactions were assessed with $\underline{F}$-tests for a twoway ANOVA (72). All were insignificant ( $p>0.05)$.

station Type by Day of Week: The interaction between the station type and the day of the week for the proportion of Healthy, Scientific, Fitness, and Weight control implied messages and the proportion of health claims is shown in Table 18. Interactions were assessed with F-tests for a twoway ANOVA (72). Interactions for the Healthy and weight Control scales were significant ( $p<.05)$ (Figures 6 and 7$)$.

From Figure 6, the network stations appeared fairly stable from Monday through Friday for the proportion of Healthy messages, averaging around .45. There was a sharp drop on saturday to .24 , and some recovery on sunday. In contrast, the proportion for the independent stations erratically peaked on Monday, Thursday, and Saturday, and fell on Tuesday and Friday.

From Figure 7, Weight Control messages for the network stations generally declined from Monday to sunday. The independent stations showed a more erratic pattern, with a high peak on Saturday and a valley on Wednesday. 
Table 17. Results of 2-way analyses of variance conducted to assess the interaction between station type and period of day for the proportion of advertisements with Healthy, Scientific, Fitness and Weight Control messages and health claims

\section{Source df Sum of Squares Mean Square $F \quad p$}

Scale: Healthy

\begin{tabular}{lrrrrr}
\hline Station Type & 1 & 1.38 & 1.38 & 5.9 & .015 \\
Period of Day & 1 & 0.52 & 0.52 & 2.2 & .136 \\
Interaction & 1 & 0.68 & 0.68 & 2.9 & .087 \\
Error & 706 & 164.02 & 0.23 & &
\end{tabular}

Scale: Scientific

\begin{tabular}{lrllll}
\hline Station Type & 1 & 0.0038 & 0.0038 & 0.3 & .559 \\
Period of Day & 1 & 0.0451 & 0.0451 & 4.1 & .044 \\
Interaction & 1 & 0.0152 & 0.0152 & 1.4 & .243 \\
Error & 706 & 7.8458 & 0.0111 & &
\end{tabular}

Scale: Fitness

$\begin{array}{lrrrrr}\text { Station Type } & 1 & 0.0789 & 0.0789 & 8.1 & .0045 \\ \text { Period of Day } & 1 & 0.0000 & 0.0000 & 0.0 & .999 \\ \text { Interaction } & 1 & 0.0083 & 0.0083 & 0.9 & .355 \\ \text { Error } & 706 & 6.8438 & 0.0097 & & \end{array}$

Scale: Weight Control

\begin{tabular}{|c|c|c|c|c|c|}
\hline $\begin{array}{l}\text { Station Type } \\
\text { Period of Day } \\
\text { Interaction } \\
\text { Error }\end{array}$ & $\begin{array}{r}1 \\
1 \\
1 \\
706\end{array}$ & $\begin{array}{r}2.944 \\
0.022 \\
0.005 \\
87.904\end{array}$ & $\begin{array}{l}2.944 \\
0.022 \\
0.005 \\
0.124\end{array}$ & $\begin{array}{r}23.6 \\
0.2 \\
0.0\end{array}$ & $\begin{array}{l}.0000 \\
.675 \\
.841\end{array}$ \\
\hline
\end{tabular}

Health Claims

$\begin{array}{lrrrrr}\text { Station Type } & 1 & 0.075 & 0.075 & 0.8 & .381 \\ \text { Period of Day } & 1 & 0.719 & 0.719 & 7.3 & .007 \\ \text { Interaction } & 1 & 0.323 & 0.323 & 3.3 & .070 \\ \text { Error } & 706 & 69.093 & 0.098 & & \end{array}$


Table 18. Results of 2-way analyses of variance conducted to assess the interaction between station type and day of week for the proportion of advertisements with Healthy, Scientific, Fitness and Weight Control messages and health claims

Source df Sum of Squares Mean Square $F$

$\mathrm{p}$

Scale: Healthy

Station Type

Day of Week

Interaction

Error

$\begin{array}{rr}1 & 1.38 \\ 6 & 1.49 \\ 6 & 3.89 \\ 696 & 159.83\end{array}$

1.38

$6.0 \quad .015$

0.25

1.1 .370

0.65

$2.8 \quad .010$

0.23

Scale: Scientific

Station Type 1

Day of Week

Interaction

Error

Scale: Fitness

station Type

Day of Week

Interaction

Error

$\begin{array}{rr}1 & 0.079 \\ 6 & 0.055 \\ 6 & 0.063 \\ 696 & 6.734\end{array}$

0.004

0.060

0.099

696

7.747

0.004

0.010

$0.3 \quad .559$

0.165

$0.9 \quad .504$

$1.5 \quad .179$

0.011

6.734

0.079

$8.2 \quad .0044$

0.009

$0.9 \quad .463$

0.011

1.1 .368

Scale: Weight Control

\begin{tabular}{|c|c|c|c|c|c|}
\hline $\begin{array}{l}\text { Station Type } \\
\text { Day of week } \\
\text { Interaction } \\
\text { Error }\end{array}$ & $\begin{array}{r}1 \\
6 \\
6 \\
696\end{array}$ & $\begin{array}{r}2.94 \\
0.22 \\
2.60\end{array}$ & $\begin{array}{l}2.94 \\
0.04 \\
0.43\end{array}$ & $\begin{array}{r}24.1 \\
0.3 \\
3.5\end{array}$ & $\begin{array}{l}.0000 \\
.94 \\
.0018\end{array}$ \\
\hline
\end{tabular}

Health Claims station Type Day of Week Interaction Error

$\begin{array}{rr}1 & 0.075 \\ 6 & 0.754 \\ 6 & 0.387 \\ 696 & 68.994\end{array}$

0.075
0.126
0.064
0.099

$0.8 \quad .384$

$1.3 \quad .268$

$0.7 \quad .692$

* statistically significant interaction $(p<.05)$. 
Proportion of Ads with a Healthy Message

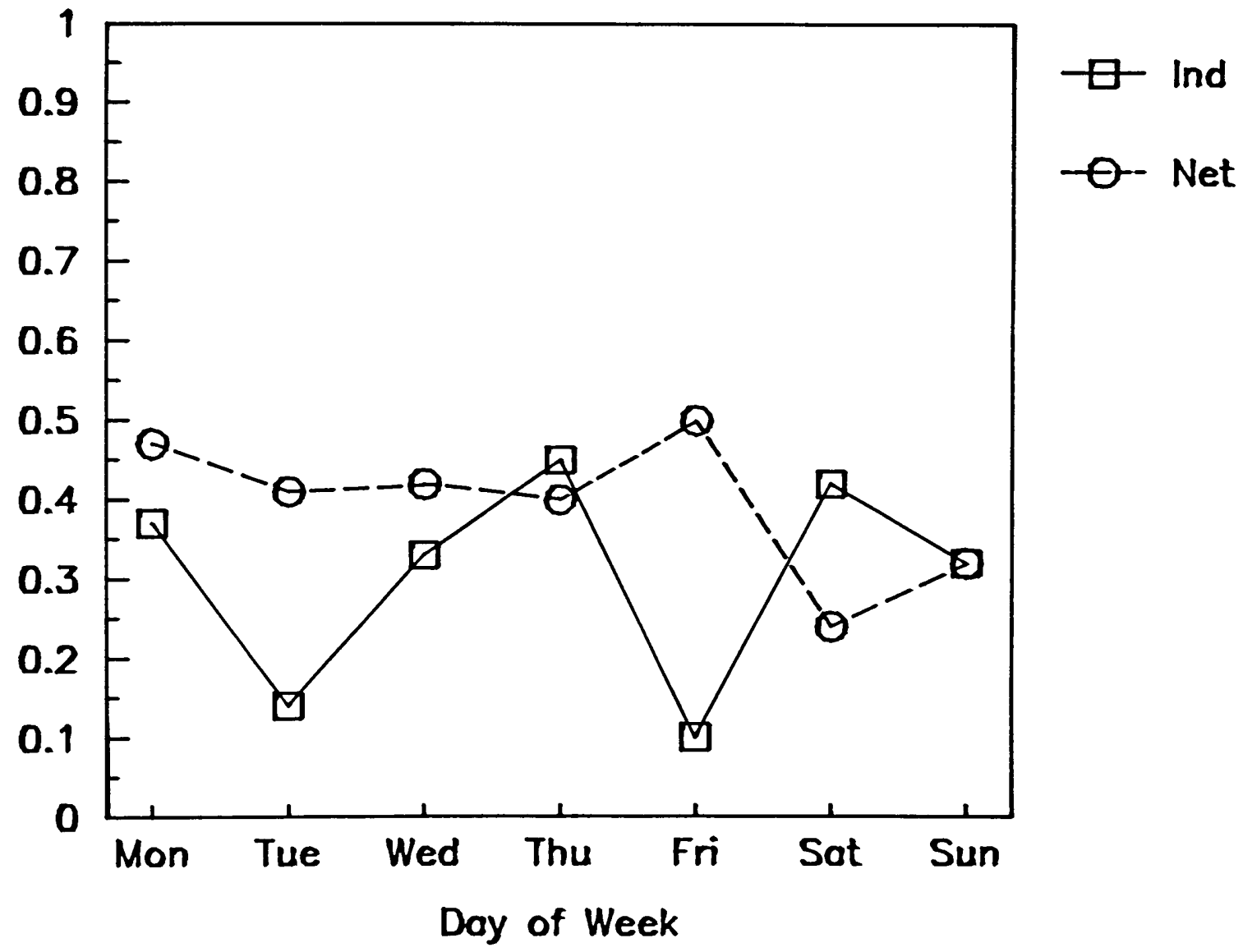

FIG. 6. Interaction between the station type and the doy of the meek for the proportion of advertisements with a Healthy message. 
Proportion of Ads with a "Weight Control" Message

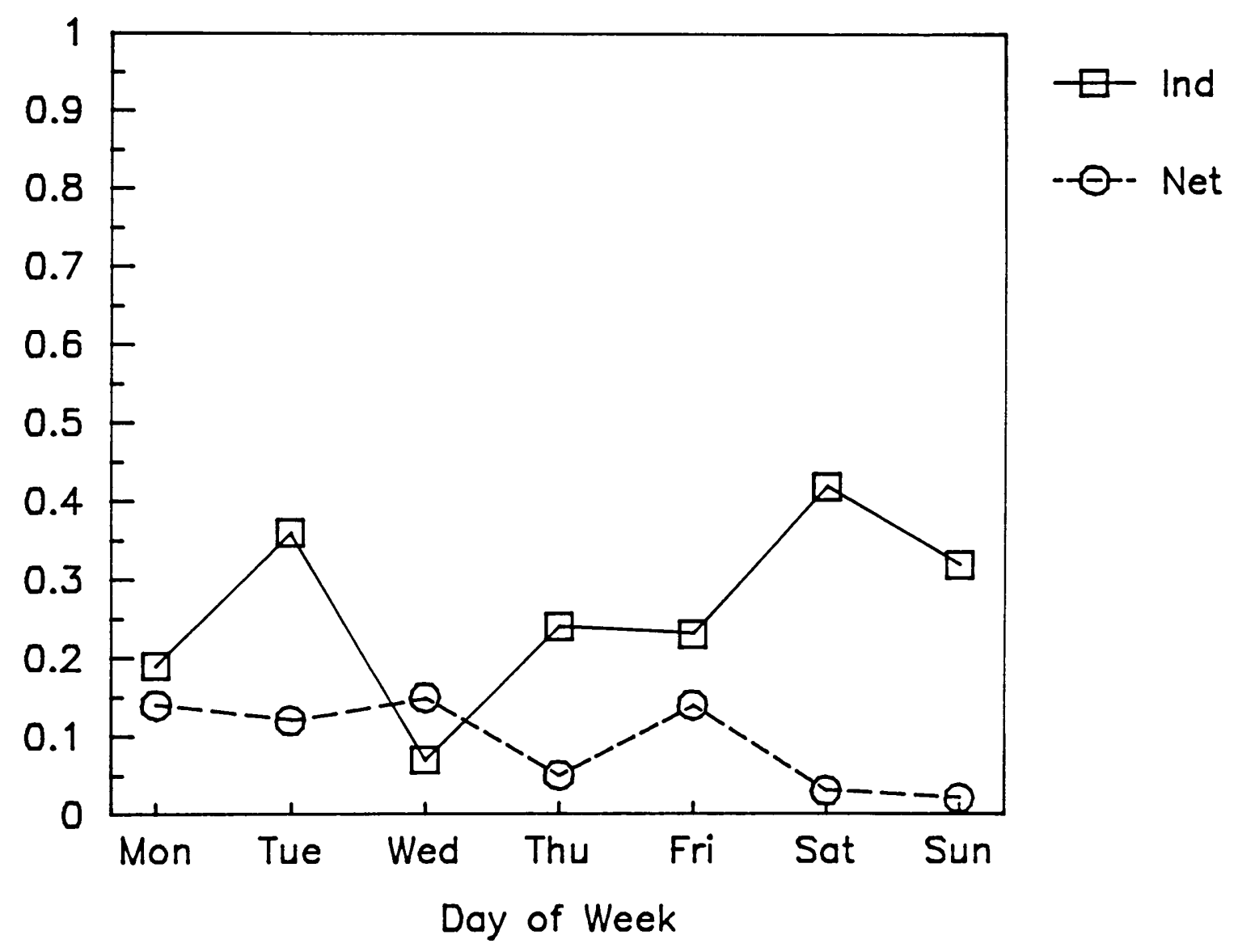

FG. 7. Interaction between the station type and the day of the week for the proportion of advertisements with a Weight Control message. 
Period of Day by Day of Week: The interaction between period of the day and day of the week for the proportion of Healthy, scientific, Fitness, and Weight control implied messages and the proportion of health claims is shown in Table 19. Interactions were assessed with F-tests for a twoway ANOVA (72). The interactions for the weight control scale and the proportions of health claims were significant $(\mathrm{p}<.05)$ (Figures 8 and 9$)$.

Figure 8 shows opposite patterns in Period 2 and 3 . Period 2 had moderate valleys on Monday and Thursday, and a sharp peak on Saturday. Period 3 showed peaks on Monday and Thursday, and a sharp valley on Saturday.

From Figure 9, Period 2 showed stronger peaks and valleys than Period 3. Period 3 curved gently, with peaks on Monday, Thursday, and Sunday, and valleys on Tuesday and saturday. Period 2 showed its strongest peak on Friday, and the strongest valley on Thursday.

Five Most Prevalent Food Classes by the Day of the Week: The pattern of the number of the five most prevalent food classes over the days of the week is shown in Figure 10. Beverage and cereal classes were similar across the days of the week (Beverage, $\underline{x}^{2}=9.5, d f=6, p=.15$; Cereal, $\underline{x^{2}=9.6}$, $\mathrm{df}=6, \mathrm{p}=.14)$. Snacks, convenience, and alcohol classes deviated significantly from straight lines (Snacks, $x^{2}=31.9$,

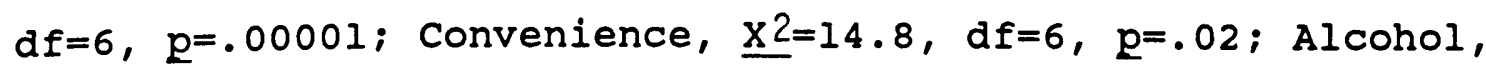
$\left.\underline{x^{2}}=12.1, d f=6, p=.05\right)$. Alcohol showed an increase in the 
Table 19. Results of 2-way analyses of variance conducted to assess the interaction between period of day and day of week for the proportion of advertisements with Healthy,

Scientific, Fitness and Weight Control messages and health claims

Source

df Sum of Squares Mean Square $F$

$\mathrm{p}$

Scale: Healthy

Period of Day

Day of Week

Interaction

Error

$\begin{array}{rr}1 & 0.79 \\ 6 & 1.12 \\ 6 & 1.55 \\ 696 & 163.14\end{array}$

0.79

$3.4 \quad .066$

0.19

$0.8 \quad .579$

0.26

$1.1 \quad .357$

Scale: Scientific

Period of Day I

Day of Week

Interaction

6
6

0.048

0.081

0.23

Error

696

0.137

7.645

0.048

$4.4 \quad .037$

0.013

1.2 .291

0.023

$2.1 \quad .054$

Scale: Fitness

Period of Day

Day of Week

Interaction

1

0.002

0.011

Error

6
6

0.051

0.002

$0.2 \quad .666$

0.052

0.009

$0.9 \quad .520$

696

6.826

0.009

$0.9 \quad .508$

Scale: Weight Control

$\begin{array}{lrrrrrr}\text { Period of Day } & 1 & & 0.014 & 0.014 & 0.1 & .740 \\ \text { Day of Week } & 6 & 0.288 & 0.048 & 0.4 & .889 \\ \text { Interaction } & 6 & 4.290 & 0.715 & 5.8 & .0000 & \text { * } \\ \text { Error } & 696 & 86.284 & 0.124 & & \\ & & & & & & \\ & & & & & & \\ \text { Health Claims } & & & & & & \\ \text { Period of Day } & 1 & 0.77 & 0.77 & 8.1 & .005 & \\ \text { Day of Week } & 6 & 0.98 & 0.16 & 1.7 & .115 & \\ \text { Interaction } & 6 & 1.82 & 0.30 & 3.2 & .004 & \text { * } \\ \text { Error } & 696 & 66.63 & 0.09 & & \end{array}$

* Statistically significant interaction $(p<.05)$. 
Proportion of Ads with a Weight Control Message

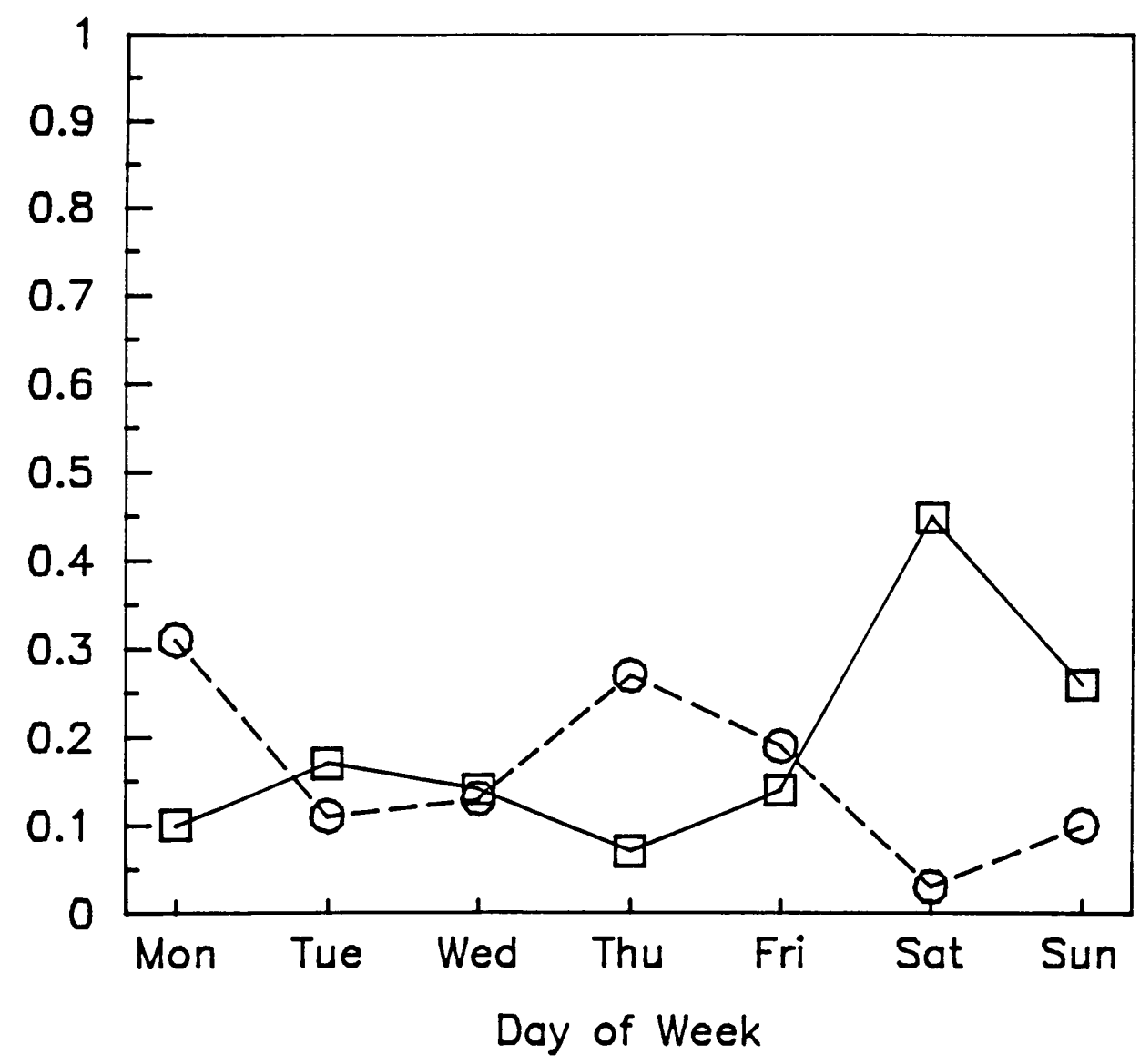

曰 Period 2

$-\Theta-$ Period 3

FIG. 8. Interaction between the period of the day and the day of the week for the proportion of advertisements with a Weight Control message. 
Proportion of Ads with a Health Claim

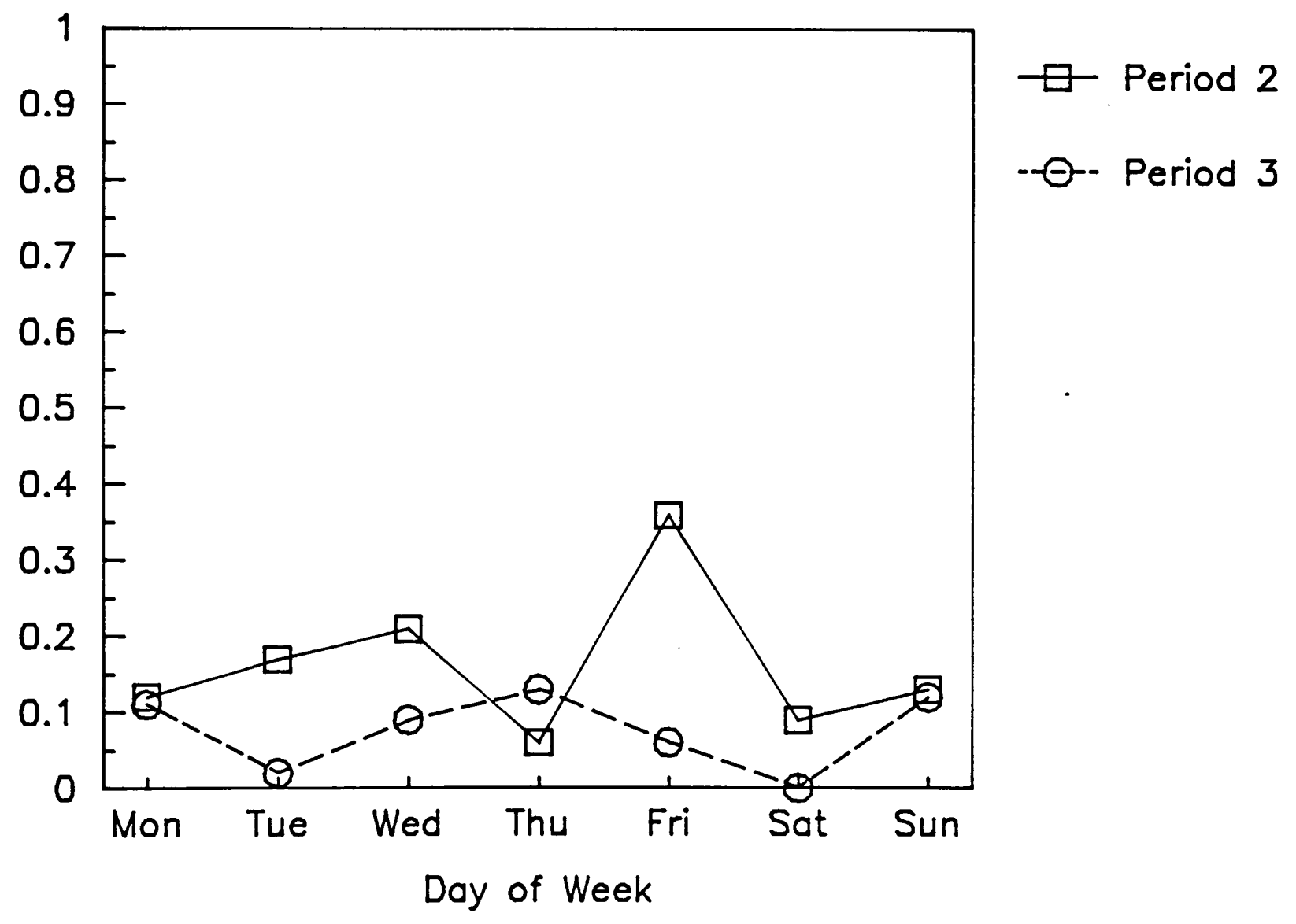

FIG. 9. Interaction between the station type and the day of the week for the proportion of advertisements with o health claim. 
Number of Ads

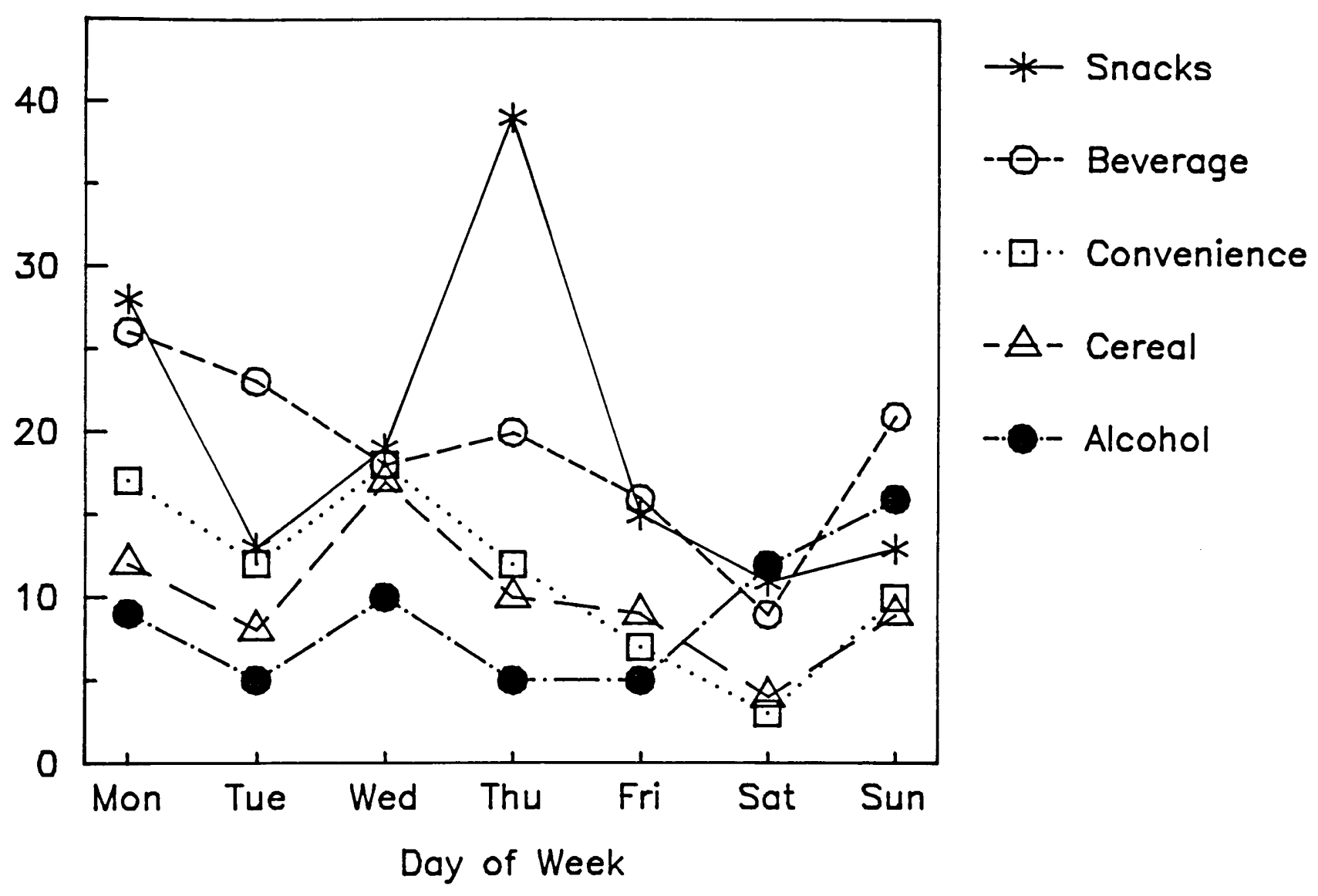

FG. 10. Distribution of the 5 most frequent food classes across the days of the week. 
number of televised advertisements from Friday to saturday. All Saturday alcohol advertisements were in the evening (Period 3).

Discussion

Frequency of Health claims: This study indicated that about $20 \%$ of television advertisements were food-related, and of these, about one in ten had a health claim. Thus, about 28 of all television advertisements contained health claims. since stations program about 16 minutes of advertisements each hour $(2,7)$, and most advertisements last 15-30 seconds, on the average about 32 to 64 advertisements per hour could be predicted. Six to 12 of these would be food advertisements. The rate of health claims presented on television is .6 to 1.2 per hour. Since most American homes have a television on about 7 hours per day (37), viewers see from 4.2 to 8.4 health claims per day, or 29 to 59 claims per week. According to this, the average American is exposed to 1500 to 3000 health claims annually in television advertisements.

Station Type: Viewers who watch local independent stations can expect to be exposed to more Weight control and Fitness messages than network viewers. The opposite was true for Healthy messages.

Period of Day: Daytime viewers (Period 2) have the potential to be exposed to more Scientific messages and health claims than evening viewers (Period 3 ). 
Days of the Week: The number of food advertisements was smaller on Saturday than other days. Viewers who watched television more on Saturday were less exposed to Healthy, Scientific, Fitness, and weight control messages and health claims. However, their greater exposure to alcohol advertisements during Period 3 (evening) may put them at greater risk for increased alcohol consumption $(43,44)$.

Cereal and snack advertisements were more frequent on Saturday morning/afternoon (Period 2) than usual. Since the most likely target audience for this period is children, this phenomenon is especially important to dietitians and consistent with published research $(34,52-54,57-62)$. In contrast to many cereal advertisements in the sample, those on Saturday morning/afternoon made no health claims. Thursday, though, seemed to be "snack day." snack advertisements were more frequent on Thursday than on any other day.

Food Class: Adams and Trachtenberg pointed out the increasing weight of American adults, and concluded that it was due to "fast food frenzy" (37). However, this study indicated that the snack class had the greatest proportion of advertisements, almost $20 \%$. Fast food accounted for only $7 \%$ of the food and nutrition advertisements.

The five most frequently advertised food classes were snacks, beverages, convenience foods, cereal, and alcohol, in that order. Together, these five classes accounted for $66 \%$ of all food advertisements. 
Even though advertisement of hard liquor is prohibited (42), alcohol advertisements were the fifth most frequent class constituting about 98 of all food and nutrition advertisements.

\section{Station Type by Day of Week Interactions: Network} viewers were exposed to the same proportion of advertisements with Healthy messages regardless of the day of the week, with the exception of a drop from Friday to saturday. Independent station viewers were exposed to a pattern which had bursts of Healthy messages on Monday, Thursday, and Saturday. If this is a deliberate advertising strategy, the rationale is not obvious.

Networks reduced their proportion of Weight Control messages on the weekend, but independent stations increased theirs. The reason for this is unclear.

Period of Day by Day of Week Interactions: The pattern for these results for the Weight Control messages was the same as that previously discussed for the station Type by Day of Week Interaction. This indicates that the previous discussion for independent stations applied specifically to independent stations during Period 2 (morning/afternoon). The greatest proportion of health claims were made on Friday during Period 2. The reason for this is also unclear. Summary of Results: A primary goal of this study was to collect information which could help dietitians use knowledge of their clients' television viewing habits to anticipate potential nutritional misconceptions. Table 20 summarizes 
the results of this study and can be used as a practical tool to accomplish this goal. Relevant viewer behaviors are listed on the left; implications for the dietitian are listed on the right. In some cases an entry has been made twice since it was appropriate under more than one major heading. 
Table 20. Possible types of nutritional misconceptions or behaviors based on client viewing habits

Client viewing habits

Types of Misconceptions or Behaviors

1. Independent station

Fitness and weight control

Monday

Health

Thursday

Health

Saturaay

Health

Weekend daytime

(Period 2)

Weight control

2. Daytime (Period 2)

Scientific messages and health claims

Friday

Health claims

Saturday

Potential "snack abuse"

Independent

weekend

Weight control

3. Thursday

Potential "snack" abuse

Independent

Health

4. Saturday

Evening

(Period 3)

Potential alcohol abuse

Daytime

Potential "snack" abuse

(Period 3)

Independent

Health 


\section{CHAPTER V}

\section{SUMMARY, CONCLUSIONS AND RECOMMENDATIONS}

SUMMARY AND CONCLUSIONS

This study investigated the messages found in food and nutrition advertisements shown on television. The goals were to determine the proportion and distribution of food and nutrition advertisements from all television advertising, to identify implied messages and health claims found in the food and nutrition commercials, and to analyze them.

A randomly selected sample of television advertisements was collected over a 28-day period beginning May 8, 1987. The sample contained 3547 advertisements of which 725 (20\%) were food-related.

This study indicated that approximately 20 percent of total advertising time is spent on food and nutrition advertisements, and about $10 \%$ of food advertisements contain a health claim. As a result of this, the average American is exposed to between 1500 and 3000 health claims each year through food and nutrition television advertisements. Keep in mind that even if the viewer is not actively participating in the advertisement, the messages may still get through (19) .

Five types of messages found in the food and nutrition advertisements were Healthy, Scientific, Fitness, Weight control, and health claims. These were analyzed for their 
dependence upon station type, time of day, day of week, and food class.

It was revealed that Healthy messages were more likely to be seen on network stations than on independent stations. Healthy messages were more often found on independent stations on Monday, Thursday, and Saturday. Viewers were more apt to be exposed to scientific messages and health claims in the morning and afternoon hours. Daytime viewers who watched television on Friday were exposed to an unusually large number of health claims.

The proportion of Weight Control messages dropped on the networks, but rose significantly on the independent stations on the weekends. Some speculations about this phenomenon follow. Viewers who watch independent stations pay a cable charge. They may represent a more affluent population with an increased concern for image and appearance. This would make the independent stations a better medium for sending Weight control messages, particularly on the weekend when the working affluent population (yuppies) may be watching their cable television.

Although the number of food and nutrition advertisements dropped significantly on saturday, the number of alcohol advertisements rose sharply on Saturday and Sunday. Snack advertisements were seen more often on Thursday, but snack commercials were also numerous on Saturday morning/afternoon, as were cereal advertisements. Advertisements for snack foods accounted for the greatest proportion of advertisements 
(208), while, contrary to the literature, fast food accounted for only 7 percent.

Snacks, beverages, convenience foods, cereal, and alcohol were the five most frequently advertised food classes; alcohol constituted about 9 percent of all food and nutrition advertisements.

Dietitians need to be aware of the messages that the public receives through television (and other media). Once dietitians know what the public is receiving in the way of food and nutrition messages, they need criteria for accuracies or inaccuracies in the message. This study showed that although dietitians agreed upon whether a health claim was present in a televised food or nutrition advertisement, their agreement was poor when they were asked to evaluate the accuracy of the claim.

RECOMMENDATIONS

Research has shown that viewers' behaviors can be influenced by advertisements $(1,2)$. The content analysis of television advertisements should help dietitians better understand the potential influence of food and nutrition advertising on clients' eating behaviors. Table 20 summarizes the findings of the content analysis. For casual conversation with clients or for use with structured interviews, this table shows the relationship between advertisers' offerings, client viewing habits, and their implications for dietitians. 
FUTURE RESEARCH

1. Dietitians did not agree with one another in their assessment of the accuracy of health claims. This suggests the need for further study. Why is the agreement among dietitians so poor for health claim accuracy? Is this result representative of the dietetic community? What steps, if any, should be taken to improve the agreement among dietitians? How does this lack of agreement generalize to dietitians' assessments of claims made in other media? How should accuracy of health claims be defined?

2. Other groups could be rated for comparison with dietitians on the 25 advertisements (e.g., anorexics, the obese, the general public). Do differences exist among groups in the way that they perceive implied messages in televised food advertisements?

3. Advertisers' strategies and rationales for placement of television advertisements should be included in future studies. Their market research plays an important role in television advertising of food.

4. Exploring correlations between viewing an advertisement and actual eating behavior has been done to a limited extent by other disciplines. Their insights would be useful to future studies. 
(1) Livingston, V.: Checking it out: Cable nets consider ad standards policy. Cable Age. C6-C9, August 19, 1985.

(2) Hanson, C. Jr.: General Sales Manager. WPTV 5, Personal Interview, February 1987.

(3) Herbert, V.: Health claims in food labeling and advertising: Literal truths but false messages; Deceptions by omission of adverse facts. Nutrition Today. 25-30, May/June 1987.

(4) Leary, J.E.: Television: The anti-wellness tool. Health Education. 16-18, September/October 1979.

(5) Glasser, W.: The Identity Society. Harper and Row Publishers, New York. 27-54, 1972 .

(6) Smith, F.A., Trivas, G., zuehlke, D.A., Lowinger, P. and Thieu, N.L.: Health information during a week of television. New England Journal of Medicine. 286:516-20, $1 \overline{972}$.

(7) Wolfmueller, D.: Advertising Sales Executive. WPEC TV 12. Personal Interview. February 1987.

(8) Carney, T.F.: Content Analysis. University of Manitoba Press. Winnepeg, Canada. 1972.

(9) -----: Zapping (switching off) commercials seems on the rise. Discount Store News. 63, May 14, 1984.

(10) -----: Madison Avenue underrates cable. Economist. 291:85-86, May 19, 1984.

(11) Giges, N. and Franz, J.: Ad budgets are fattened for 186 pushes. Advertising Age. 3,81, February 24, 1986.

(12) Dagnoli, J.: G.F. shifts more to ads for 1987. Advertising Age. 1,106, November 3, 1986.

(13) LeRoux, M.: Advertisers and cable: marriage made in heaven. Advertising Age. 48, May 31, 1984.

(14) Rosenzweig, H.: Eight reasons to advertise on cable. Broadcasting. 22, September 22, 1986.

(15) -----: FC\&B's Blaine taps industry's collective wisdom. Marketing \& Media Decisions. 120-24, February 1984 . 
(16) Myers, J.: Networks stake survival on ad revenues. Advertising Age. 30-32, May 31, 1984.

(17) Spot Television Service: Johnny-on-The-Spot. Broadcast Advertisers' Reports, Inc., January 1987. National Register Publishing Co. Illinois. 1987.

(19) Krugman, H.E.: Low recall and high recognition of advertising. Journal of Advertising Research. 26:79-86, 1986.

(20) Samuelsohn, A.: Cowboys, giants and lemmings: 25 years of T.V. commercials. Backstage. 25:5,60, 1985.

(21) Information Division: National Association of Broadcasters of the Better Business Bureau [NAB]. Personal Phone Contact. September 1987.

(22) Schwerin, H.: Quoted in Media Scope. 56-57, April 1967.

(23) La Barbera, P.: Consumers and the Federal Trade Commission: An empirical investigation. The Board of Trustees of Michigan State University. 11-17, 1977.

(24) Dahringer, L.D., and Johnson, D.R.: The Federal Trade Commission redefinition of deception and public policy implications: Let the buyer beware. Journal of Consumer Affairs. $18: 326-342,1984$.

(25) Food and Drug Administration: Public health messages on food labels and labeling. Federal Register. 52:28843, August 4, 1987.

(26) Gordon, R.L.: Food ads take on a renewed priority at FTC. Advertising Age. 3,57, February 6, 1984.

(27) Colford, S.W.: FDA policy targets food health claims. Advertising Age. 20,101, October 28, 1985.

(28) Colford, S.W.: FDA shows new taste for food health claims. Advertising Age. 3,72, December 9, 1985.

(29) -----: Cancer society wary of food ads with diet tieins. Advertising Age. 1,68, February 20, 1984.

(30) Horn, B.: When being a vegetable doesn't mean a thing. U.S. News and World Report. 6, March 23, 1987.

(31) Schroeder, A.J.: Health claims in advertising: An industry perspective. American Journal of Clinical Nutrition. 44:567-570, 1986 . 
(32) Editorial: FDA needs running shoes. Advertising Age. 18, April 15, 1985.

(33) Glasser, W.: Stations of the Mind. Harper and Row Publishers, New York. 4-7, 1981.

(34) Whitney, E.N., and Hamilton, E.M.N.: Understanding Nutrition. West Publishing Company, Minnesota. 1987.

(35) Burton, B.T., and Foster, W.R.: Health implications of obesity: An NIH Consensus Development Conference. Journal American Dietetic Association. 85(9):1117-1121, 1985.

(36) Haggerty, P.A. and Blackburn, G.L.: A critical evaluation of popular low calorie diets in America: Part 2. Topics in Clinical Nutrition. 2:37-46, 1987.

(37) Adams, J.R. and Trachtenberg, J.A.: Losing the battle of the bulge. Forbes. 166-172, November 17, 1986.

(38) Falciglia, G.A. and Gussow, J.D.: Television commercials and eating behavior of obese and normal weight women. Journal of Nutrition Education. $12: 196-99$, 1980 .

(39) Glasser, W.: Positive Addiction. Harper and Row Publishers, New York. $2,1976$.

(40) Ornstein, S.I., and Hanssens, D.M.: Alcohol control laws and the consumption of distilled spirits and beer. Journal of Consumer Research. 12:200-213, 1985.

(41) Richmond, J.B.: Healthy people: The Surgeon-General's report on health promotion and disease prevention. Government Printing office, 1979.

(42) Singer, D.G.: Alcohol, television, and teenagers. Pediatrics. Supplement:4 (Part 2):668-674, 1985.

(43) Tucker, L.: Television's role regarding alcohol use among teenagers. Adolescence. 20:593-598, 1985.

(44) Atkin, C., Hocking, J., and Block, M.: Teenage drinking: Does advertising make a difference? Journal of Communications. 157-167, Spring, 1984 .

(45) Wallack, L., Breed, W., and Cruz, J.: Alcohol on primetime television. Journal of Studies on Alcohol. 48:3338,1987 .

(46) Atkin, C., Neuendorf, K., and McDermott, S.: The role of alcohol advertising in excessive and hazardous drinking. Journal of Drug Education. 13:313-325, 1983. 
(47) Sobell, L.C., et al.: Effect of television programming and advertising on alcohol consumption in normal drinkers. Journal of studies on Alcohol. 47:333-340, 1986.

(48) Board of Trustees Report: Alcohol: Advertising, Counteradvertising, and depiction in the public media. Journal American Medical Association. 256:1485-1488, 1986.

(49) Stoneman, Z., and Brody, G.H.: Peers as mediators of television food advertisements aimed at children. Developmental Psychology. 17:853-858, 1981.

(50) Federal Trade Commission: FTC staff report on television advertising to children. U.S. Government Printing office, 1978 .

(51) Barcus, F.E.: Saturday children's television: A report of TV programming and advertising on Boston commercial television. Action For Children's Television. 1971.

(52) Gussow, J.: Counternutritional messages of TV ads aimed at children. Journal of Nutrition Education. 4:48-52, 1972 .

(53) Galst, J.P. and White, M.A.: The unhealthy persuader: the reinforcing value of television and children's purchase-influencing attempts at the supermarket. Child Development. 47:1089-96, 1976.

(54) Barcus, F.E.: Weekend commercial children's television. Action For Children's Television. 1975.

(55) Faber, R.J., Meyer, T.P. and Miller, M.M.: The effectiveness of health disclosures within children's television commercials. Journal of Broadcasting. $28(4): 463-76,1984$.

(56) Ward, T.B.: Opinions on television advertising to children: a content analysis of letters to the Federal Trade Commission. Merrill-Palmer Quarterly. $30(3): 247-59$, 1984 .

(57) Dietz, W.H., Jr., and Gortmaker, S.L.: Do we fatten our children at the television set? Obesity and television viewing in children and adolescents. Pediatrics. $75: 807-812$, 1985 .

(58) Dorr, A.: Children's advertising rule-making comment. Testimony to the Federal Trade Commission's Rulemaking Hearings on Television Advertising and Children, San Francisco, California. 1978. 
(59) Robertson, T., and Rossiter, J.: Children and commercial persuasion: an attribution theory analysis. Journal of Consumer Research. 1:13-20, 1974 .

(60) Sheikh, A., Prasad, V., and Rao, T.: Children's TV commercials: A review of research. Journal of Communications. 24:126-136, 1974 .

(61) Sprafkin, J., Gadow, K.D., and Dussault, M.: Reality perceptions of television: A preliminary comparison of emotionally disturbed and non-handicapped children. American Journal of Orthopsychiatry. 56:147-152, 1986.

(62) Palmer, E.L. and McDowell, C.N.: Children's understanding of nutritional information presented in breakfast cereal commercials. Journal of Broadcasting. 25:295-301, 1981 .

(63) Clancy, K.L.: Preliminary observations on media use and food habits of the elderly. Gerontologist. 529-32, December 1975.

(64) Schutz, H.G., Baird, P.C., and Hawkes, G.R.: Lifestyles and Consumer Behavior of older Americans. Praeger Publishers, A Division of Holt, Rinehart and Winston/CBS Inc. New York. 1979.

(65) Schlenker, E.D.: Nutrition in Aging. Times Mirror/ Mosby College Publishing, st. Louis. 1984.

(66) Guthrie, H., Black, K. and Madden, J.P.: Nutritional practices of elderly citizens in rural Pennsylvania. Gerontologist. 330-35, December 1972 .

(67) Parasuraman, A.: Marketing Research. Addison-Wesley Publishing Company, Inc. 412-414, 1986.

(68) Walpole, R.E.: Elementary Statistical Concepts. Macmillan Publishing Co., Inc., N.Y., 131-32, 1976.

(69) Bradley, J.V.: Probability, Decision, Statistics. Prentice-Hall, Inc., Englewood Cliffs, 1976.

(70) CRUNCH Software Corporation: CRunch Interactive Statistical Package (CRISP). CRUNCH Software Corporation, San Francisco, 1986.

(71) Fleiss, J.L.: Statistical Methods for Rates and Proportions. John Wiley, New York, 1981 .

(72) Myers, J.L.: Fundamentals of Experimental Design. Allyn and Bacon, Boston, 1979. 
APPENDIX A. Sampling Schedule

\begin{tabular}{|c|c|c|c|c|}
\hline Day & station & Cable Channel & Start & Time \\
\hline 1 & $\begin{array}{l}\text { WTVJ-4 } \\
\text { USA } \\
\text { WTBS }-17\end{array}$ & $\begin{array}{r}4 \\
23 \\
17\end{array}$ & $\begin{array}{l}1200 \\
1800 \\
2000\end{array}$ & $\begin{array}{l}\text { (12PM) } \\
\text { (6PM) } \\
\text { (8PM) }\end{array}$ \\
\hline 2 & $\begin{array}{l}\text { WPLG-10 } \\
\text { WTBS-17 } \\
\text { WTBS }-17\end{array}$ & $\begin{array}{l}25 \\
17 \\
17\end{array}$ & $\begin{array}{l}1200 \\
1400 \\
2200\end{array}$ & $\begin{array}{l}(12 \mathrm{PM}) \\
(2 \mathrm{PM}) \\
(10 \mathrm{PM})\end{array}$ \\
\hline 3 & $\begin{array}{l}\text { WDZL-39 } \\
\text { WSVN-7 }\end{array}$ & $\begin{array}{r}19 \\
7\end{array}$ & $\begin{array}{r}600 \\
1000\end{array}$ & $\begin{array}{l}(6 \mathrm{AM}) \\
(10 \mathrm{AM})\end{array}$ \\
\hline 4 & $\begin{array}{l}\text { WTVJ-4 } \\
\text { WPEC-12 } \\
\text { USA }\end{array}$ & $\begin{array}{r}4 \\
12 \\
23\end{array}$ & $\begin{array}{l}1200 \\
1400 \\
2200\end{array}$ & $\begin{array}{l}\text { (12 PM) } \\
(2 \mathrm{PM}) \\
\text { (1OPM) }\end{array}$ \\
\hline 5 & $\begin{array}{l}\text { WOR-9 } \\
\text { WTVX-34 } \\
\text { WFLX-29 }\end{array}$ & $\begin{array}{r}11 \\
8 \\
3\end{array}$ & $\begin{array}{r}600 \\
1800 \\
2000\end{array}$ & $\begin{array}{l}(6 \mathrm{AM}) \\
(6 \mathrm{PM}) \\
(8 \mathrm{PM})\end{array}$ \\
\hline 6 & $\begin{array}{l}\text { WPLG-10 } \\
\text { WOR-9 } \\
\text { WPTV-5 }\end{array}$ & $\begin{array}{r}25 \\
11 \\
5\end{array}$ & $\begin{array}{r}800 \\
1400 \\
2200\end{array}$ & $\begin{array}{l}\text { ( } 8 \mathrm{AM}) \\
(2 \mathrm{PM}) \\
(10 \mathrm{PM})\end{array}$ \\
\hline 7 & $\begin{array}{l}\text { A\&E } \\
\text { WOR-9 } \\
\text { WPEC-12 }\end{array}$ & $\begin{array}{l}20 \\
11 \\
12\end{array}$ & $\begin{array}{r}600 \\
1200 \\
1400\end{array}$ & $\begin{array}{l}(6 \mathrm{AM}) \\
(12 \mathrm{PM}) \\
(2 \mathrm{PM})\end{array}$ \\
\hline 8 & $\begin{array}{l}\text { WTVJ-4 } \\
\text { USA } \\
\text { WTVX-34 }\end{array}$ & $\begin{array}{r}4 \\
23 \\
8\end{array}$ & $\begin{array}{r}800 \\
1400 \\
1600\end{array}$ & $\begin{array}{l}(8 \mathrm{AM}) \\
(2 \mathrm{PM}) \\
(4 \mathrm{PM})\end{array}$ \\
\hline 9 & $\begin{array}{l}\text { A\&E } \\
\text { WPTV -5 }\end{array}$ & $\begin{array}{r}20 \\
5\end{array}$ & $\begin{array}{r}200 \\
1600\end{array}$ & $\begin{array}{l}(2 \mathrm{AM}) \\
(4 \mathrm{PM})\end{array}$ \\
\hline 10 & $\begin{array}{l}\text { WTBS-17 } \\
\text { WSVN-7 } \\
\text { WPTV-5 }\end{array}$ & $\begin{array}{r}17 \\
7 \\
5\end{array}$ & $\begin{array}{r}600 \\
800 \\
1400\end{array}$ & $\begin{array}{l}(6 \mathrm{AM}) \\
(8 \mathrm{AM}) \\
(2 \mathrm{PM})\end{array}$ \\
\hline 11 & $\begin{array}{l}\text { WDZL-39 } \\
\text { WTVX-34 }\end{array}$ & $\begin{array}{r}19 \\
8\end{array}$ & $\begin{array}{l}1600 \\
2000\end{array}$ & $\begin{array}{l}(4 \mathrm{PM}) \\
(8 \mathrm{PM})\end{array}$ \\
\hline 12 & $\begin{array}{l}\text { WTVJ-4 } \\
\text { WOR-9 } \\
\text { USA }\end{array}$ & $\begin{array}{r}4 \\
11 \\
23\end{array}$ & $\begin{array}{r}800 \\
1000 \\
2000\end{array}$ & $\begin{array}{l}(8 \mathrm{AM}) \\
(10 \mathrm{AM}) \\
(8 \mathrm{PM})\end{array}$ \\
\hline 13 & $\begin{array}{l}\text { WPEC-12 } \\
\text { WFLX }-29\end{array}$ & $\begin{array}{r}12 \\
3\end{array}$ & $\begin{array}{l}1600 \\
2000\end{array}$ & $\begin{array}{l}(4 \mathrm{PM}) \\
(8 \mathrm{PM})\end{array}$ \\
\hline
\end{tabular}




\begin{tabular}{|c|c|c|c|c|}
\hline Day & station & Cable Channel & $\underline{\text { start }}$ & E Time \\
\hline 14 & $\begin{array}{l}\text { A\&E } \\
\text { WPTV-5 }\end{array}$ & $\begin{array}{r}20 \\
5\end{array}$ & $\begin{array}{r}400 \\
1600\end{array}$ & $\begin{array}{l}(4 \mathrm{AM}) \\
(4 \mathrm{PM})\end{array}$ \\
\hline 15 & $\begin{array}{l}\text { USA } \\
\text { WSVN-7 }\end{array}$ & $\begin{array}{r}23 \\
7\end{array}$ & $\begin{array}{r}800 \\
1400\end{array}$ & $\begin{array}{l}(8 \mathrm{AM}) \\
(2 \mathrm{PM})\end{array}$ \\
\hline 16 & $\begin{array}{l}\text { WTBS-17 } \\
\text { WTVJ-4 } \\
\text { WSVN-7 }\end{array}$ & $\begin{array}{r}17 \\
4 \\
7\end{array}$ & $\begin{array}{l}1000 \\
1200 \\
2000\end{array}$ & $\begin{array}{l}(10 A M) \\
(12 \mathrm{PM}) \\
(8 \mathrm{PM})\end{array}$ \\
\hline 17 & $\begin{array}{l}\text { WTVJ -4 } \\
\text { A\&E }\end{array}$ & $\begin{array}{r}4 \\
20\end{array}$ & $\begin{array}{l}1200 \\
1400\end{array}$ & $\begin{array}{l}\text { (12PM) } \\
\text { (2PM) }\end{array}$ \\
\hline 18 & $\begin{array}{l}\text { WDZL-39 } \\
\text { WPTV-5 }\end{array}$ & $\begin{array}{r}19 \\
5\end{array}$ & $\begin{array}{l}1200 \\
1600\end{array}$ & $\begin{array}{l}(12 \mathrm{PM}) \\
(4 \mathrm{PM})\end{array}$ \\
\hline 19 & $\begin{array}{l}\text { A\&E } \\
\text { WPLG-10 }\end{array}$ & $\begin{array}{l}20 \\
25\end{array}$ & $\begin{array}{l}1800 \\
2000\end{array}$ & $\begin{array}{l}(6 \mathrm{PM}) \\
(8 \mathrm{PM})\end{array}$ \\
\hline 20 & $\begin{array}{l}\text { WPEC-12 } \\
\text { WPTV }-5 \\
\text { A\&E }\end{array}$ & $\begin{array}{r}12 \\
5 \\
20\end{array}$ & $\begin{array}{l}1200 \\
1800 \\
2200\end{array}$ & $\begin{array}{l}\text { (12PM) } \\
(6 \mathrm{PM}) \\
(10 \mathrm{PM})\end{array}$ \\
\hline 21 & $\begin{array}{l}\text { USA } \\
\text { WPLG-10 } \\
\text { WTVX-34 }\end{array}$ & $\begin{array}{r}23 \\
25 \\
8\end{array}$ & $\begin{array}{r}600 \\
800 \\
2200\end{array}$ & $\begin{array}{l}(6 A M) \\
(8 A M) \\
(10 P M)\end{array}$ \\
\hline 22 & $\begin{array}{l}\text { USA } \\
\text { WPEC-12 } \\
\text { WFLX-29 }\end{array}$ & $\begin{array}{r}23 \\
12 \\
3\end{array}$ & $\begin{array}{r}600 \\
2000 \\
2200\end{array}$ & $\begin{array}{l}(6 \mathrm{AM}) \\
(8 \mathrm{PM}) \\
(10 \mathrm{PM})\end{array}$ \\
\hline 23 & $\begin{array}{l}\text { WOR-9 } \\
\text { WTVX-34 }\end{array}$ & $\begin{array}{r}11 \\
8\end{array}$ & $\begin{array}{r}000 \\
1400\end{array}$ & $\begin{array}{l}\text { (12AM) } \\
\text { (2PM) }\end{array}$ \\
\hline 24 & $\begin{array}{l}\text { WFLX }-29 \\
\text { WSVN-7 }\end{array}$ & $\begin{array}{l}3 \\
7\end{array}$ & $\begin{array}{l}1400 \\
1800\end{array}$ & $\begin{array}{l}\text { (2PM) } \\
(6 \mathrm{PM})\end{array}$ \\
\hline 25 & $\begin{array}{l}\text { WOR-9 } \\
\text { WPLG-10 } \\
\text { WTBS-17 }\end{array}$ & $\begin{array}{l}11 \\
25 \\
17\end{array}$ & $\begin{array}{l}1400 \\
1600 \\
2200\end{array}$ & $\begin{array}{l}\text { (2PM) } \\
\text { ( } 4 \mathrm{PM}) \\
(1 \mathrm{OPM})\end{array}$ \\
\hline 26 & $\begin{array}{l}\text { WDZL-39 } \\
\text { WFLX-29 } \\
\text { WSVN-7 }\end{array}$ & $\begin{array}{r}19 \\
3 \\
7\end{array}$ & $\begin{array}{r}000 \\
1400 \\
1600\end{array}$ & $\begin{array}{l}(12 \mathrm{AM}) \\
(2 \mathrm{PM}) \\
\text { (4 PM) }\end{array}$ \\
\hline 27 & $\begin{array}{l}\text { WFLX }-29 \\
\text { WTVX-34 } \\
\text { WPEC-12 }\end{array}$ & $\begin{array}{r}3 \\
8 \\
12\end{array}$ & $\begin{array}{r}000 \\
1600 \\
2200\end{array}$ & $\begin{array}{l}(12 \mathrm{AM}) \\
(4 \mathrm{PM}) \\
(10 \mathrm{PM})\end{array}$ \\
\hline 28 & $\begin{array}{l}\text { WDZL-39 } \\
\text { WPLG-10 }\end{array}$ & $\begin{array}{l}19 \\
25\end{array}$ & $\begin{array}{l}400 \\
800\end{array}$ & $\begin{array}{l}(4 \mathrm{AM}) \\
(8 \mathrm{AM})\end{array}$ \\
\hline
\end{tabular}


Channel:

Tape Number:

Ad Food/Nutrition

Counter Program

Advertisement
Food Class

Counter Range:

From:

To:

Heal th Claims? Implied Messages Descriptor Words 
APPENDIX C: Descriptor List for Implied Messages Scales

1. The Senses

$$
\begin{aligned}
& \text { senses } \\
& \text { taste } \\
& \text { refreshing } \\
& \text { fresh } \\
& \text { clear } \\
& \text { good } \\
& \text { tempting } \\
& \text { spicy } \\
& \text { satisfying }
\end{aligned}
$$

rich

flavorful

fruity

alive

clean

light

pure

succulent

lively

crisp

texture

crispy

chewy

crunchy

thick

creamy

juicy

fluffy

smooth

spreadable

temperature

hot

cool

cold

frosty

smell

aroma

2. Hearty/Satisfying

hearty

satisfying

filling 
3. Healthy

health

real

natural

pure

nutritious

healthy

wholesome

sugar-free

goodness

digestible

enriched

complete

balanced

nutrition

illness

prevention

4. Science

scientific

knowledgeable

doctor-recommended

professional

assured

safety

successful

5. Fitness

fitness

endurance

strength

competition

6. Weight-control/Beauty

weight-control

beauty

appearance

slenderness

sexuality

magical

low-calorie

7. Macho

macho

tough

strong 
8. Sex

sex

hot

love

9. Youth

youth

10. Adult

adult

sophisticated

11. Fun

fun

playful

action

vitality

energy

12. Peer Pressure

peer

pressure

acceptance

popular

highly-rated

favorite

13. Friendship

friendship

friendly

camaraderie

14. Family-values

family-values

family

love

caring

tenderness

reminiscence

homemade

original

homey

belonging

involvement

old-fashioned

earthy 
15. Trendy

trend

new

fashionable

futuristic

modern

16. Traditional

traditional

patriotic

tradition

American

dedicated

trustworthy

17. Convenience

convenience

easy

fast

clean

convenient

18. Value

value

good-buy

free

prize

charitable

quantity

large

size

19. Special/Luxury

special

luxury

classy

classic

quality

elegance

original

chef's

wealth

superior

gourmet

tasteful

different

perfect

foreign

exceptional 
20. Variety/Choice

variety

choice

21. Extraordinary Claim

extraordinary-claims

paradise

unbel ievable

sinful

religious

spiritual

unordinary

mysterious

heavenly

22. Product Comparison

comparison 
APPENDIX D: Instructions, Implied Messages Form (Likert Scales), and Health claims Questionnaire

Instructions

Thank you for agreeing to participate in this study. You will be asked to watch and evaluate 25 food advertisements. These advertisements have been recorded on a videotape cassette. As you watch the advertisements, please stop the tape after each advertisement and evaluate it using the two forms which have been provided for each advertisement.

The first form is for Implied Messages. It has 22 sevenpoint scales. Please check a position on each scale indicating the degree to which you feel the advertisement emphasized the scale's implied message, such as "The senses" or "Beauty/Weight Control". A "l" is the lowest degree of emphasis and a "7" is the highest. To help you understand the types of descriptors used to create the scales, please read the descriptor list on the following two pages. After the descriptor list, there is a sample Implied Messages form.

Following each Implied Messages form will be a Health claims form. If a health claim was made in the advertisement, please use this form to indicate what the health claims were, and whether any of them were inaccurate. A sample Health claims form follows the sample Implied Messages form.

The advertisement number and product are printed on each form to aid in keeping track of the advertisements and forms.

If, while you are watching the tape, you want to watch an advertisement again, please feel free to do so. However, I am primarily interested in your immediate reactions, so please don't feel that you have to view any; advertisement more than once. If you are watching the tape with another participant, please do not discuss the advertisements or influence each other in any way until you have completed all the forms.

Remember, I want your honest opinions regarding the advertisements. You are not being evaluated; we are all cooperating to evaluate the advertisements.

Again, I want to thank you very much for taking the time to participate in the study. 
Implied Messages Form (Likert Scales)

Advertisement Number: 0

Product: Example

Emphasizes

Degree of Emphasis

$\frac{\text { Emphasizes }}{1 \quad \text { The senses }}$

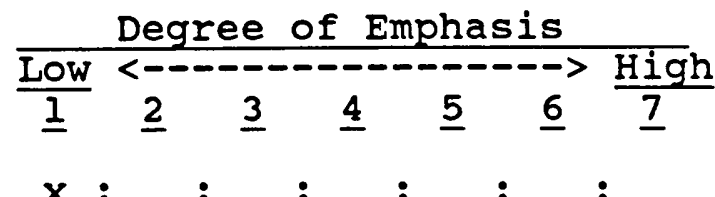

2 Hearty/satisfying

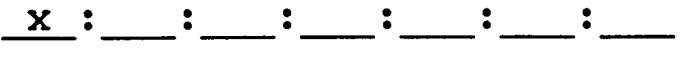

3 Healthy

4 Scientific

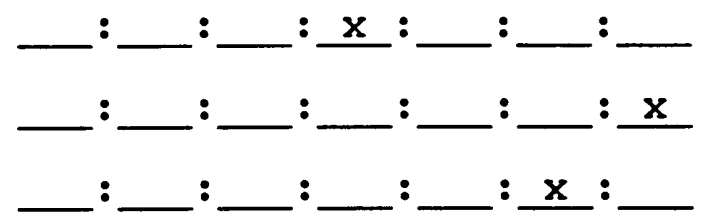

$5 \quad$ Fitness

6 Beauty/

Weight Control

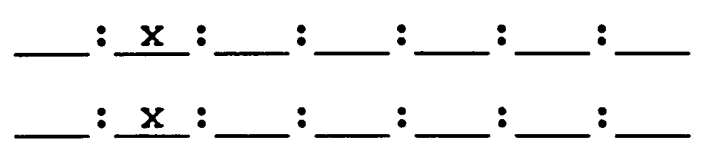

7 Macho

8 Sex

9 Youth

10 Adult

11 Fun

12 Peer Pressure

13 Friendship

14 Family Values

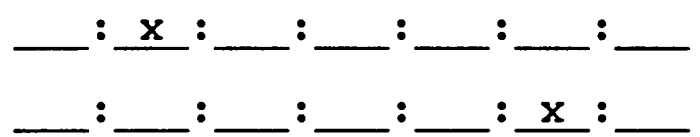

15 Trendy

16 Traditional

17 Convenience

18 value

19 Special/Luxury
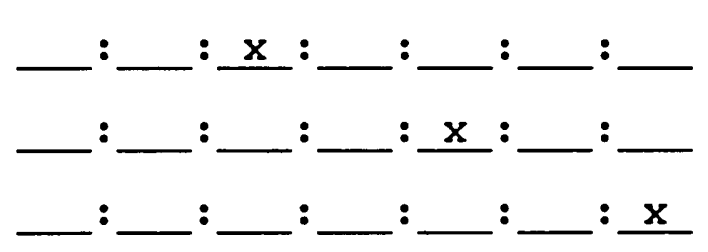

20 Variety/Choice

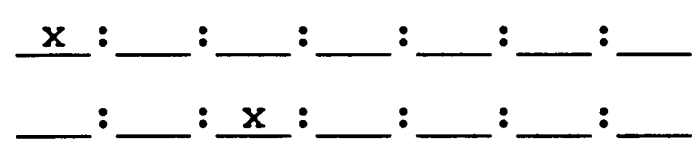

21 Extraordinary

Claim
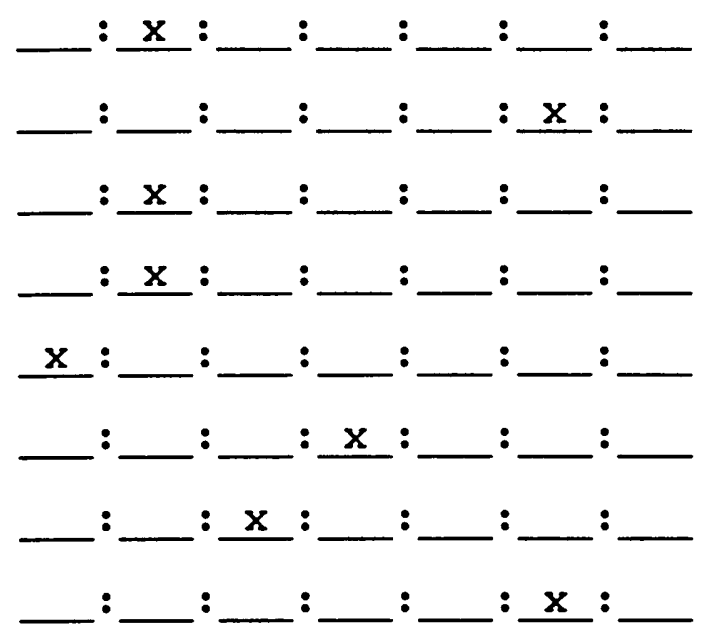

22 Product

Comparisons

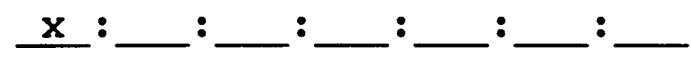


Health Claims Questionnaire

Advertisement Number: $0 \quad$ Product: Example

1. Does the advertisement make any health claims?

Yes $\quad x$ No

If yes, please list the claims.

2. Are the health claims, if any, accurate?

Yes $\quad$ No $\quad x$ N/A

If no, please list the inaccuracies. 